\title{
Returning Samples From Enceladus for Life Detection
}

\author{
Marc Neveu ${ }^{1,2 *}$, Ariel D. Anbar ${ }^{3,4}$, Alfonso F. Davila ${ }^{5}$, Daniel P. Glavin ${ }^{1}$, \\ Shannon M. MacKenzie ${ }^{6}$, Charity M. Phillips-Lander ${ }^{7}$, Brent Sherwood ${ }^{8}$, \\ Yoshinori Takano ${ }^{9}$, Peter Williams ${ }^{4}$ and Hajime Yano ${ }^{10}$
}

\begin{abstract}
${ }^{1}$ Solar System Exploration Division, NASA Goddard Space Flight Center, Greenbelt, MD, United States, ${ }^{2}$ Department of Astronomy, University of Maryland, College Park, MD, United States, ${ }^{3}$ School of Earth \& Space Exploration, Arizona State University, Tempe, AZ, United States, ${ }^{4}$ School of Molecular Sciences, Arizona State University, Tempe, AZ, United States, ${ }^{5}$ NASA Ames Research Center, Moffett Field, Mountain View, CA, United States, ${ }^{6}$ Applied Physics Laboratory, Johns Hopkins University, Laurel, MD, United States, ${ }^{7}$ Space Science and Engineering Division, Southwest Research Institute, San Antonio, TX. United States, ${ }^{8}$ Blue Origin, Seattle, WA, United States, ${ }^{9}$ Japan Agency for Marine-Earth Science \& Technology, Yokosuka, Japan, ${ }^{10}$ Institute of Space and Astronautical Science, Japan Aerospace Exploration Agency, Sagamihara, Japan
\end{abstract}

\section{OPEN ACCESS}

Edited by:

Isik Kanik,

NASA Jet Propulsion Laboratory (JPL), United States

Reviewed by:

Teresa Fornaro Osservatorio Astrofisico di Arcetri (INAF), Italy

Armando Azua-Bustos, Consejo Superior de Investigaciones Cientificas (CSIC), Spain

${ }^{*}$ Correspondence: Marc Neveu marc.fneveu@nasa.gov

Specialty section: This article was submitted to Astrobiology,

a section of the journal Frontiers in Astronomy and Space Sciences

Received: 03 March 2020 Accepted: 06 May 2020

Published: 06 August 2020

Citation:

Neveu M, Anbar AD, Davila AF,

Glavin DP, MacKenzie SM Phillips-Lander CM, Sherwood B, Takano $Y$, Williams $P$ and Yano $H$ (2020) Returning Samples From

Enceladus for Life Detection.

Front. Astron. Space Sci. 7:26 doi: 10.3389/fspas.2020.00026
Evidence suggests that Saturn's icy moon Enceladus has a subsurface ocean that sources plumes of water vapor and ice vented to space from its south pole. In situ analyses of this material by the Cassini spacecraft have shown that the ocean contains key ingredients for life (elements $\mathrm{H}, \mathrm{C}, \mathrm{N}, \mathrm{O}$ and possibly S; simple and complex organic compounds; chemical disequilibria at water-rock interfaces; clement temperature, pressure, and $\mathrm{pH}$ ). The Cassini discoveries make Enceladus' interior a prime locale for life detection beyond Earth. Scant material exchange with the inner Solar System makes it likely that such life would have emerged independently of life on Earth. Thus, its discovery would illuminate life's universal characteristics. The alternative result of an upper bound on a detectable biosphere in an otherwise habitable environment would likewise considerably advance our understanding of the prevalence of life beyond Earth. Here we outline the rationale for returning vented ocean samples, accessible from Enceladus' surface or low altitudes, to Earth for life detection. Returning samples allows analyses using laboratory instruments that cannot be flown, with decades or more to adapt and repeat analyses. We describe an example set of measurements to estimate the amount of sample to be returned and discuss possible mission architectures and collection approaches. We then turn to the challenges of preserving sample integrity and implementing planetary protection policy. We conclude by placing such a mission in the broader context of Solar System exploration.

Keywords: Enceladus, astrobiology, sample return, life detection, ocean worlds, icy satellites

\section{INTRODUCTION}

Evidence suggests that Saturn's tiny moon Enceladus (radius $252 \mathrm{~km}$ ) has a subsurface ocean that sources plumes of water vapor and ice vented to space from its south pole. The composition of vented material arguably provides the strongest evidence to date of a habitable environment beyond Earth, with liquid water, the major elements for life, a biologically usable energy source, and clement physicochemical conditions (section "Evidence That Enceladus Is Habitable"). 
The eruption of ocean material not only allows the study of Enceladus' ocean and its habitability without having to penetrate under its icy surface, it also offers the chance to test the hypothesis that evidence for life is present at detectable levels in the plume (McKay et al., 2014). A positive detection could provide the first unambiguous evidence for life beyond Earth, with a likely independent emergence given the dearth of material exchange between Enceladus and the inner Solar System (Worth et al., 2013; Melosh, 2019). This would point to a universality of biology and provide a second data point to identify universal characteristics of life. The alternative result could be the first instance of a habitat where signs of life are not detected, placing a constraint on the detectability of biospheres beyond Earth (the $f_{l}$ factor in the Drake equation; Burchell, 2006).

To search for life in the plume, mission concepts ranging from in situ analyses (Lunine et al., 2015; MacKenzie et al., 2016; Eigenbrode et al., 2018), to orbiting or landing (MacKenzie et al., 2020), to sample return (Tsou et al., 2012; Sekine et al., 2014) have been proposed or discussed, as steps on a path (Sherwood, 2016) toward in situ characterization of subsurface liquid (Konstantinidis et al., 2015). In addition to scientific interest, recent political will in the United States has spurred roadmapping of the exploration of "ocean worlds" (Enceladus is a prime example) to search for life (Hendrix et al., 2019). To inform such planning activities for future astrobiology exploration, there is a need to define and constrain the spectrum of possible architectures for each class of missions (flyby, landed, with or without sample return) beyond specific concepts. There is also a need to identify technical and policy issues that must be addressed for these missions to be implemented.

In this paper, we focus on the return of a plume sample, following up on Sekine et al. (2014) and Takano et al. (2014). First, we briefly review the evidence on Enceladus' habitability and rationalize the value of sample return for life detection. We then estimate how much sample would have to be returned in order to perform a suite of measurements able to assess the presence of life in the samples. Next, we discuss a spectrum of sample return mission architectures. We outline outstanding technical and policy issues in the realization of such a mission and conclude by placing Enceladus sample return in the broader context of Solar System exploration.

\section{EVIDENCE THAT ENCELADUS IS HABITABLE}

\section{Liquid Water}

The plume of water vapor and icy grains emanating from Enceladus' south polar terrain was discovered early in the Cassini mission at Saturn (Hansen et al., 2006; Porco et al., 2006; Spahn et al., 2006; Waite et al., 2006). Subsequent imaging showed that the plume was fed by a combination of jets (Spitale and Porco, 2007; Porco et al., 2014) and a more diffuse curtainlike source (Spitale et al., 2015), both closely associated with four linear fractures dubbed "tiger stripes." The plume density is linked to Enceladus' orbital position around Saturn, suggesting that eruptions are controlled by tides (Hedman et al., 2013).
Mass spectrometry measurements revealed the composition of plume vapor (Waite et al., 2006, 2009, 2017) and grains (Postberg et al., 2009, 2011, 2018a; Hsu et al., 2015; Khawaja et al., 2019). Together, these measurements strongly suggest that the plume material originates in a subsurface ocean that is in contact with Enceladus' rocky core. This ocean seems to be global according to gravity-, shape-, and libration-based determinations of Enceladus' internal structure (Iess et al., 2014; Thomas et al., 2016; Hemingway and Mittal, 2019).

\section{Major Elements for Life C, H, N, O (and S?)}

The plume vapor contains hydrocarbons of molecular mass/charge ratio up to at least 100, the upper bound on the Cassini instrument range (Waite et al., 2009). These are likely the fragments of more complex organic species, some containing $\mathrm{N}$ and $\mathrm{O}$ functional groups (Khawaja et al., 2019), detected up to and above masses of 200 atomic mass units (amu) in plume grains (Postberg et al., 2018a). The vapor also contains carbon in the form of $\mathrm{CO}_{2}, \mathrm{CH}_{4}$, and perhaps $\mathrm{CO}$. It contains nitrogen in the form of $\mathrm{NH}_{3}$ and $\mathrm{HCN}$, which are known chemical precursors of amino acids and other more complex organic compounds of prebiotic relevance, and perhaps $\mathrm{N}_{2}$ (indistinguishable from $\mathrm{CO}$ in Cassini data). These $\mathrm{C}$ and $\mathrm{N}$ species are present at abundances of $0.1-1 \%$ relative to $\mathrm{H}_{2} \mathrm{O}$. Sulfur may be present as $\mathrm{H}_{2} \mathrm{~S}$, tentatively quantified at about 30 ppm with respect to $\mathrm{H}_{2} \mathrm{O}$ (Waite et al., 2009; Bouquet et al., 2015) but not unambiguously disentangled from species with the same mass of $34 \mathrm{amu}$ (e.g., $\mathrm{H}_{2} \mathrm{O}_{2}$ ). Thus, of the six major elements key to life on Earth (“CHNOPS”), four (perhaps five) have been detected in Enceladus' ocean material as species which, on Earth, are food substrates for chemotrophic life. $\mathrm{C}$ and $\mathrm{N}$ are more abundant per unit volume than in Earth's oceans (Cable et al., 2020). P is likely present in the rocky core, since it is part of planet-building materials such as carbonaceous chondrite meteorites (e.g., Wasson and Kallemeyn, 1988), and probably very partially dissolved into the ocean at abundances below the limit of detection of Cassini instruments (section "Availability of phosphorus and Trace Elements").

\section{Biologically Usable Energy}

In addition to vapor, the plume contains icy particles. About $20 \%$ of particles (by number) are nearly pure water ice. About $40 \%$ are made of ice bearing percent-level organic or siliceous material. The rest is composed of ice bearing 0.5-2 mass\% of sodium and potassium salts (Postberg et al., 2011, 2018a). Particles of similar composition, but with a higher proportion of ice-rich grains, are also observed in Saturn's E-ring which is fed by the plume (Postberg et al., 2008, 2009). Further out in the Saturn system, stream particles thought to originate from the E-ring (and thus from Enceladus' interior) have been interpreted as being made of nanometer-sized silica (Hsu et al., 2015). Silica nanoparticles can form when hot fluids with dissolved silica encounter colder water in which silica is less soluble. These particles can grow to micron sizes within 1,000 years. This timing, together with short travel times in the Saturn system, suggests that hydrothermal activity is currently occurring inside Enceladus (Hsu et al., 2015). The formation of silica nanoparticles 
was reproduced in the laboratory by reacting liquid water with carbonaceous chondritic material. These experiments constrain hydrothermal fluid temperatures to above $50^{\circ} \mathrm{C}$ and $\mathrm{pH}$ up to 10.5 , provided that silica precipitates upon mixing into the cold $\left(\approx 0^{\circ} \mathrm{C}\right)$ ocean with a $\mathrm{pH}$ between 8.5 and 10.5 (Hsu et al., 2015; Sekine et al., 2015). Modeling of the plume composition suggests that Enceladus' ocean pH is in this range (Glein et al., 2018; Glein and Waite, 2020). This supports the potential hydrothermal formation pathway for silica nanoparticles.

Water-rock interaction is consistent with internal structure models derived from Cassini data (Hemingway and Mittal, 2019 and references therein) that suggest Enceladus' ocean surrounds a porous rocky core possibly permeated with liquid water (Choblet et al., 2017; Neveu and Rhoden, 2019). At these conditions on Earth, the interaction of relatively oxidizing water (as evidenced by the presence of $\mathrm{CO}_{2}$ in the plume) with reducing rock produces hydrogen, providing energy for chemoautotrophic life (Schulte et al., 2006; Russell et al., 2010). The detection of $\mathrm{H}_{2}$ in Enceladus' plume has confirmed that water-rock interactions are ongoing (Waite et al., 2017).

\section{Environmental Conditions Compatible With Life}

The temperatures of liquid water on Enceladus seem to range between its freezing point under a few kilometers of ice $\left(\approx 0^{\circ} \mathrm{C}\right)$ and $90^{\circ} \mathrm{C}$ or more for silica to be solubilized in water permeating the rocky core (Sekine et al., 2015). Corresponding pressures span the range $0.5-600$ bar. The lower bound is the hydrostatic pressure at $0.5-1 \mathrm{~km}$ depth, i.e., $\sim 10 \%$ of the possible ice thickness near the south pole corresponding to the top of the water table in vents. The upper bound is the sum of hydro- and lithostatic pressures in the core, assuming a $55 \mathrm{~km}$ thick ocean+ice layer surrounding a core with radius $195 \mathrm{~km}$ and density $2,400 \mathrm{~kg}$ $\mathrm{m}^{-3}$ (Hemingway and Mittal, 2019). Ocean salinity likely ranges between 0.5 and $2 \%$ as inferred from the composition of saltbearing grains in the plume (Postberg et al., 2011). This is slightly lower than Earth's oceans. The $\mathrm{pH}$ has been inferred to be in the broad range 8-12 (Glein et al., 2015; Sekine et al., 2015), with the current best estimate at 8.5-9 (Glein and Waite, 2020). Except for the $\mathrm{pH} 12$ endmember, the temperatures, pressures, salinity, and $\mathrm{pH}$ inferred for Enceladus' ocean are in ranges that not only do not come close to pushing the limits of life as we know it (e.g., Takai et al., 2008; Inagaki et al., 2015), but also closely match those of known ecosystems on Earth (Kelley et al., 2005; Imachi et al., 2020).

\section{Remaining Uncertainties}

\section{Sufficient Amount of Time for Life to Emerge}

There is uncertainty as to whether life can emerge in a subsurface ocean, a hypothesis which is testable by a life detection mission to Enceladus (Deamer and Damer, 2017). Conditions compatible with life have likely existed on Enceladus for as long as there has been liquid water in its interior (ocean and/or pore spaces in the core). Was this a sufficient amount of time for life to emerge? Life started on Earth in less than a billion years (Dodd et al., 2017), providing an upper bound, but the minimum time is not well-constrained (Orgel, 1998) and could have been orders of magnitude smaller. The duration of liquid water on Enceladus too is seldom constrained.

Enceladus' current activity suggests that it has had liquid water for decades to $\sim 1$ million years at a minimum. The plume has been directly observed since 2005. Tentative photographic evidence of the E-ring (sourced by the plume) was acquired as the Earth crossed the plane of Saturn's rings in 1966 (Feibelman, 1967; Kuiper, 1974; Smith et al., 1975). Feibelman (1967 and references therein) noted that "during the second half of the nineteenth century a number of visual observations were reported." Although evidence from the Pioneer 11 Saturn flyby in 1979 was equivocal (Larson et al., 1981), the E-ring's existence was confirmed from ground-based observations during the 1979 ring plane crossing by the Earth (Baum et al., 1981; Larson et al., 1981 and references therein) and the Voyager 1 flyby (Stone and Miner, 1981). A recent formation model for the parallel tiger stripes suggests that these formed due to crust breaking under the weight of plume fallback accumulated over $\sim 1$ Myr (Hemingway et al., 2019).

The only known heat source able to maintain water liquid on tiny Enceladus is from the dissipation of tides raised by Saturn. Where energy is dissipated is uncertain: water flowing through a permeable rocky core (Choblet et al., 2017), ocean movement damped by the overlying ice (Tyler, 2020), and/or recently increased equilibrium forcing of the ice shell if Enceladus' orbit is expanding at a nearly constant rate due to changes in Saturn's interior (Nimmo et al., 2018; Lainey et al., 2020). Each mechanism could alone sustain the current ocean. However, none suggests a precise enough path to Enceladus' present state as to constrain how long water has been liquid.

Another upper bound on the ocean age could arise from the lack of chemical equilibrium among species detected in the plume. On geological timescales, $\mathrm{H}_{2}$ and $\mathrm{CO}_{2}$ should equilibrate with $\mathrm{H}_{2} \mathrm{O}$ and $\mathrm{CH}_{4}$ to reach concentrations different from those measured (McCollom, 2016; Waite et al., 2017). This may suggest that the plume $\mathrm{H}_{2}$ and $\mathrm{CO}_{2}$ originate in distinct locations of water-rock interaction in a core of heterogeneous composition (Glein and Waite, 2020). It is unclear whether this points to a geologically young ocean or instead to incomplete chemical homogenization of the core due to limited pervasiveness of fluid circulation (Macdonald and Fyfe, 1985; Cable et al., 2020). A better chronometer could be provided by measuring abundances of organic compound classes that decompose in water on a variety of timescales (Truong et al., 2019). Mineral or organic chemical tracers of the ocean age can be tracked with measurements synergistic with life detection (section "Measurement Strategy and Sample Needed").

\section{Availability of Phosphorus and Trace Elements}

Among bioessential elements, $\mathrm{P}$ and trace elements (e.g., $\mathrm{Fe}$ ) have yet to be detected. Estimates of their abundances require an assumption on the bulk composition of rock in Enceladus' interior since none of these elements are thought to be supplied in ices. Plausible analogous rocks of known composition are chondrite meteorites, whose $\mathrm{P}$ and trace elements abundances are representative of the bulk Solar System. Interaction of chondritic rock with ice melts yields minerals and volatile species similar to 
those observed in Enceladus' plume (e.g., Zolotov, 2007; Neveu et al., 2017).

If these assumptions are correct, and Enceladus' ocean was in chemical equilibrium with its rocky core (bulk water:rock mass ratio of $\approx 0.4$ assuming a $30 \mathrm{~km}$-thick ocean overlying a hydrated core $190 \mathrm{~km}$ in radius with $30 \mathrm{vol} \%$ water-filled porosity), ocean P concentrations would be $\sim 1 \mu \mathrm{mol} \mathrm{kg}{ }^{-1}$ (Neveu et al., 2017). This is 10 to 100 times higher than in Earth's ocean, despite most $\mathrm{P}$ being sequestered in the core owing to the low solubility of phosphates. However, as shown by the presence of $\mathrm{H}_{2}$ in the plume (Waite et al., 2017), the ocean and core are not currently in equilibrium. Estimates of steady-state P concentrations that account for source and sink fluxes are 100-1,000 times lower than Earth's ocean (Lingam and Loeb, 2018). This could make $\mathrm{P}$ a limiting nutrient unless there is a steady flux (e.g., aided by hydrothermal circulation) of $\mathrm{P}$ into the ocean and it is efficiently scavenged there by biomass (Cable et al., 2020), or unless the ocean $\mathrm{pH}$ and oxidation state are such that $\mathrm{P}$ is present as phosphites, which are $\approx 1,000$ times more soluble than phosphates (Pasek, 2008). Assumptions of equilibrium or steady state both suggest that $\mathrm{Fe}$ is unlikely to be present at much lower abundances than in Earth's ocean, i.e., $\sim 0.1 \mathrm{nmol} \mathrm{kg}^{-1}$ (Neveu et al., 2017; Lingam and Loeb, 2018).

The reverse issue of too high availability of trace elements, leading to their potential toxicity, is another unknown. The determination of the abundances of a broad suite of elements is synergistic with life-detection measurements (section "Measurement Strategy and Sample Needed").

\section{Energy Supply Limitation}

Any biosphere in Enceladus' subsurface ocean is likely limited by its supply of energy. A plausible energy source is the catalysis of the oxidation-reduction reaction of $\mathrm{CO}_{2}$ and $\mathrm{H}_{2}$, or of reactions involving the organic compounds observed in the plume. These are known to sustain (sub-)seafloor ecosystems on Earth. On Enceladus, their viability as energy sources rests on estimates of the rates (i.e., fluxes) at which reactants such as $\mathrm{H}_{2}$ are produced (Steel et al., 2017; Taubner et al., 2018; Cable et al., 2020), ratioed to rates of biomass energy use for growth and maintenance of organismal or community functions (Hoehler and Jørgensen, 2013). The compounded uncertainties in Enceladus supply and biological demand leads to an eight order-of-magnitude range of estimates in the biomass that could be sustained per $\mathrm{mL}$ of Enceladus ocean (Cable et al., 2020). Even the highest values $\left(\sim 1,000\right.$ cells $\left.\mathrm{cm}^{-3}\right)$ are two to three orders of magnitude lower than in Earth's ocean $\left(10^{5}-10^{6}\right.$ cells $\mathrm{cm}^{-3}$; Whitman et al., 1998).

\section{Enceladus' Habitability: Summary}

Measurements to date suggest that Enceladus' ocean fulfills all the requirements to sustain life. Uncertainties remain regarding how long these ingredients have been present together and how large of a biosphere can be sustained given the limited supply of energy and phosphorus. These limitations suggest that Enceladus' biosphere, if it exists, has a biomass density at least 100-1,000 times lower than Earth's. A stricter upper bound on biomass could be estimated from Enceladus' higher organic carbon content ( $\leq 1 \%$; Waite et al., 2009; Postberg et al., 2018a) relative to the $0.5 \mathrm{ppm}$ total organic carbon of Earth's ocean (Thurman, 1985). The latter is kept low because biomass is consuming it. All else (e.g., metabolic rates, no plume enrichment in organic compounds upon eruption) being equal, the higher organic carbon content of Enceladus' ocean would imply that its biomass density is $10^{4}$ times smaller $\left(<100\right.$ cells $\left.\mathrm{cm}^{-3}\right)$. The level of understanding of habitability at Enceladus makes it ripe for a life-detection mission (Hendrix et al., 2019; Figure 1). This is widely appreciated (Lunine et al., 2015; Porco et al., 2017; Eigenbrode et al., 2018). Next, we discuss the merits of sample return for life detection.

\section{SAMPLE RETURN: ADVANTAGES AND CHALLENGES}

Sample return presents both unique advantages and unique challenges for life detection (McKay et al., 2014; Treiman, 2017; Table 1). Returning samples of ejected Enceladus ocean material would uniquely enable investigations that can be adapted as results are obtained, are exquisitely sensitive, and leverage improvements in measurement capabilities for decades to come.

\section{Adaptable Analyses}

With returned samples, the next measurement can be devised based on the results of the previous one (Shearer and Borg, 2006; McKay et al., 2014), with ample time to think through the path of analysis and with all existing instrumental techniques available. Laboratory measurements and analytical techniques can also be adapted to sample properties, repeated multiple times, and checked with other analytical techniques. Such unmatched adaptability has proven crucial in previous searches for biomarkers and assessments of their biogenicity, which can take years even if the sample is in the laboratory. This includes the time needed for independent validation of measurements by different research teams, refutation of claims, or follow-on hypothesis-driven measurements, which proceed at the pace of journal publications. The path to every confirmed or refuted claim of life detection in samples of ancient (e.g., Schopf, 1993), extraterrestrial (McKay et al., 1996), or otherwise secluded environments (Priscu et al., 1999) has taken years of subsequent, initially unplanned analyses. Previous life detection endeavors have taught us to expect the unexpected. These precedents have set a high bar to convince the community of a detection of life: life must be the only possible explanation for the measurement results (Klein, 1978; Neveu et al., 2018 and references therein).

In this context, in situ life detection presents the risk that the mission payload finds tantalizing clues but cannot carry out needed follow-on measurements. As versatile as flight instruments can be, their capabilities are frozen in at the time of mission design, years ahead of the measurements, with a preconception of what could be measured. This leaves limited ability to adapt the measurement strategy to new results gathered by the mission. The alternative is then to wait for a subsequent mission, possibly far in the future as illustrated by the 40year gap between the Viking and Mars Science Laboratory 


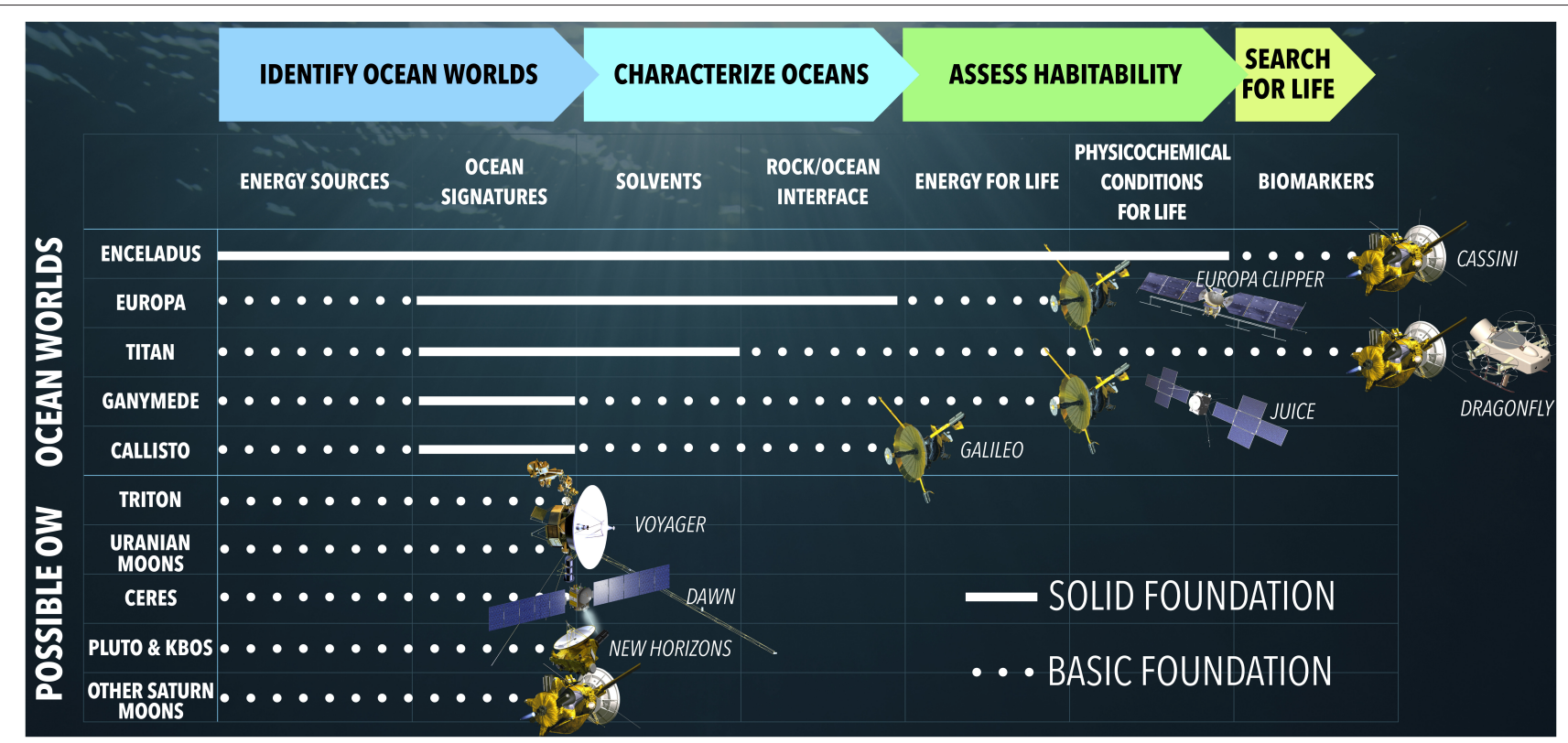

FIGURE 1 | Enceladus is farthest along the roadmap to understanding the potential of ocean worlds to harbor life (Hendrix et al., 2019). White lines across roadmap milestones depict the current state of knowledge for each world or class of worlds from past exploration by the Cassini, Galileo, Voyager, Dawn, and New Horizons spacecrafts (from top to bottom). Upcoming missions such as Europa Clipper (NASA) to Europa, JUICE (ESA) to Ganymede, and Dragonfly (NASA) to Titan will make further progress along this roadmap. Modified from Hendrix et al. (2019) under the terms of a CC BY 4.0 license.

TABLE 1 | Relative merits of in situ and sample return missions for life detection.

\begin{tabular}{|c|c|c|}
\hline & In situ life detection & $\begin{array}{l}\text { Life detection in } \\
\text { returned samples }\end{array}$ \\
\hline $\begin{array}{l}\text { Advantages for } \\
\text { life detection }\end{array}$ & $\begin{array}{l}\text { - Contextual } \\
\text { understanding } \\
\text { - Sample minimally } \\
\text { altered }\end{array}$ & $\begin{array}{l}\text { - Adaptable analyses } \\
\text { - Unmatched } \\
\text { instruments } \\
\text { - Archival }\end{array}$ \\
\hline $\begin{array}{l}\text { Drawbacks for } \\
\text { life detection }\end{array}$ & $\begin{array}{l}\text { - Inflexible measurement } \\
\text { capabilities } \\
\text { - Limited space-proof } \\
\text { instruments }\end{array}$ & $\begin{array}{l}\text { - Lack of contextual } \\
\text { understanding } \\
\text { - Sample alteration } \\
\text { between collection and } \\
\text { measurement }\end{array}$ \\
\hline
\end{tabular}

An in situ mission with a sample return element, or two complementary missions (in sequence or in parallel) have the advantages of both and none of the drawbacks (Shearer and Borg, 2006).

investigations of indigenous organic compounds on Mars (Klein, 1978; Eigenbrode et al., 2018).

In contrast, an example of a challenging but eventually successful measurement is that of the carbon isotopic composition of the amino acid glycine to establish its cometary origin in samples of comet Wild 2 returned by the Stardust mission. Determination of the abundance and carbon isotopic composition of glycine required (a) hot water extraction from the Stardust collector aerogel and foils to recover the material soluble in water including amino acids, followed by drying; (b) acid vapor hydrolysis of the water-extracted residue to free amino acids bound to salts or other cations and/or generated from acid-hydrolyzable precursors (Glavin et al., 2006); (c) multi-step derivatization, including inter-step decantation to remove insoluble residue interfering with sample injection, to convert amino acids to more volatile derivatives able to be separated in a gas chromatography column (e.g., Martins et al., 2007); (d) measurement of the amino acid derivatives separated by gas chromatography using combustion isotope ratio mass spectrometry (Elsila et al., 2009); and (e) recovery of the actual isotopic abundances from the measured values by removing biases introduced during derivatization using measurements acquired on derivatized and underivatized standards. The optimization of the analytical procedures for the carbon isotopic analysis of trace amino acids extracted from Stardust foils took 3 years to implement in the laboratory. Neither the sample preparation steps (optimized iteratively) nor compound-specific isotopic analysis of amino acids can be carried out with current spaceflight instruments.

\section{Use of Instruments That Cannot Be Flown}

Returned samples can be analyzed with instruments that cannot be flown (Figure 2). These include:

1. Instruments of higher performance than those that can be flown at any given time. For example, mass spectrometers that could be flown to Enceladus today exceed the capabilities of Cassini's instruments by one order of magnitude in mass range, two in mass resolution, and four in sensitivity (Lunine et al., 2015; Brockwell et al., 2016). Similarly, ongoing developments are expected to outperform current flight capabilities by, e.g., two more orders of magnitude in mass resolution (Arevalo et al., 2018). 


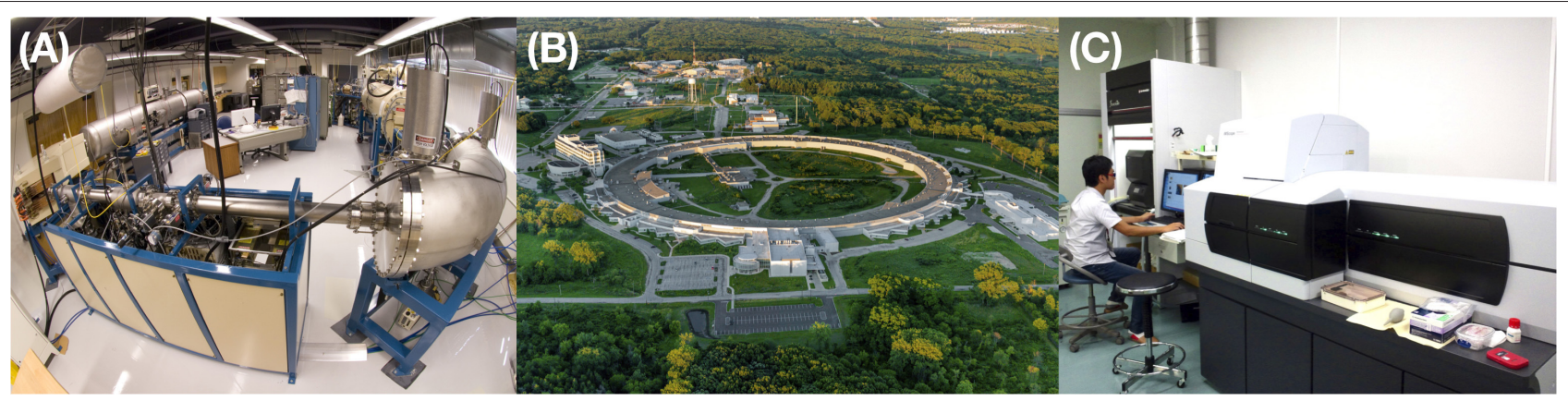

FIGURE 2 | Example techniques that greatly enhance life detection but cannot be flown. (A) Secondary lon/Accelerator Mass Spectrometer for isotopic measurements on small samples proximal to surface contamination, built and used for the Genesis mission. Credit: NASA (public domain). (B) Aerial view of a synchrotron X-ray source used, e.g., for microscale X-ray diffraction. Credit: Argonne National Laboratory, reproduced under a CC BY-NC-SA 2.0 license. (C) Matrix-Assisted Laser Desorption/lonization (MALDI)-Imaging Mass Microscope. Credit: JAMSTEC.

2. Instruments that cannot be miniaturized (Figure 2). The most performant instruments on Earth for key life detection measurements (e.g., compound-, position-, and/or spatially specific isotopic analyses; atom-by-atom imaging) can take up a room (nanoscale secondary ion mass spectrometry, atom probe tomography; e.g., Branson et al., 2016) or a facility (Xray synchrotron; e.g., Nakamura et al., 2008). More detail on techniques and their capabilities is provided in Table 3.

3. Complex wet chemistry protocols or sample preparation steps (e.g., section "Adaptable Analyses"; Figure 5),

4. A much more diverse suite of techniques than could be accommodated on any spacecraft.

\section{Archival}

Allocating returned material for archival enables analyses with techniques that cannot be conceived of at the time of mission design. This is illustrated by analyses of archived lunar samples collected during the Apollo missions that keep on yielding insights with ways of investigating samples that could not be fathomed in the 1970s (Shearer and Borg, 2006). These methods include preliminary examination by non-destructive techniques such as X-ray computed tomography, micro X-ray fluorescence, and imaging micro-Raman spectroscopy to optimize detailed analyses based on the spatial distribution of compositional units within the sample (Zeigler et al., 2019).

An example scientific result is the determination of the varying propensity of individual mineral grains to retain radiogenic argon in lunar samples (Mercer et al., 2019). This use of electron probe microanalysis and spatially resolved laser ablation noble gas mass spectrometry was only possible decades after the end of Apollo. It provides direct implications for the dating of lunar material that currently anchors much of the absolute ages tentatively determined across planetary surfaces in the solar system.

\section{Challenges}

Challenges germane to sample return include:

- Understanding the samples' geological context with measurements carried out off-site,
- Minimizing sample alteration during capture and transport from the sampling location to the laboratory and recording the conditions (e.g., pressure, temperature) of the sample's environment from collection through Earth return,

- Avoiding sample contamination by life on Earth and its byproducts,

- Backward contamination in the context of planetary protection ("Restricted Earth Return"),

- Sample preservation in curation.

Understanding context requires in situ science to be carried out either as part of the sample return or with a separate, complementary, dedicated mission (Shearer and Borg, 2006; Figure 3). A thorough in situ study of plume material would also establish a necessary baseline from which any alterations due to sample return can be identified. This dual need makes an in situ mission a logical precursor to sample return (Figure 3), as has been the case in Mars exploration, unless the needed in situ measurements are performed by the sample return mission. The latter approach may be sensible given the comparatively long trip times to Enceladus. In situ life detection science at Enceladus, including context, has been discussed elsewhere (Lunine et al., 2015; Eigenbrode et al., 2018; MacKenzie et al., 2020). The other four challenges, inherent to any astrobiology sample return mission, are discussed in section "Technical and Policy Considerations."

\section{MEASUREMENT STRATEGY AND SAMPLE NEEDED}

Modern measurement strategies for life detection in extraterrestrial material have been discussed in detail elsewhere (e.g., Summons et al., 2008; Hand et al., 2017; Neveu et al., 2018; Glavin et al., 2019). In brief, they target multiple attributes (potential "biosignatures") that distinguish biological from abiotic properties or processes. This includes material that can comprise living organisms such as:

- Over-representation of amino acids with high molecular mass and structural isomer preference 


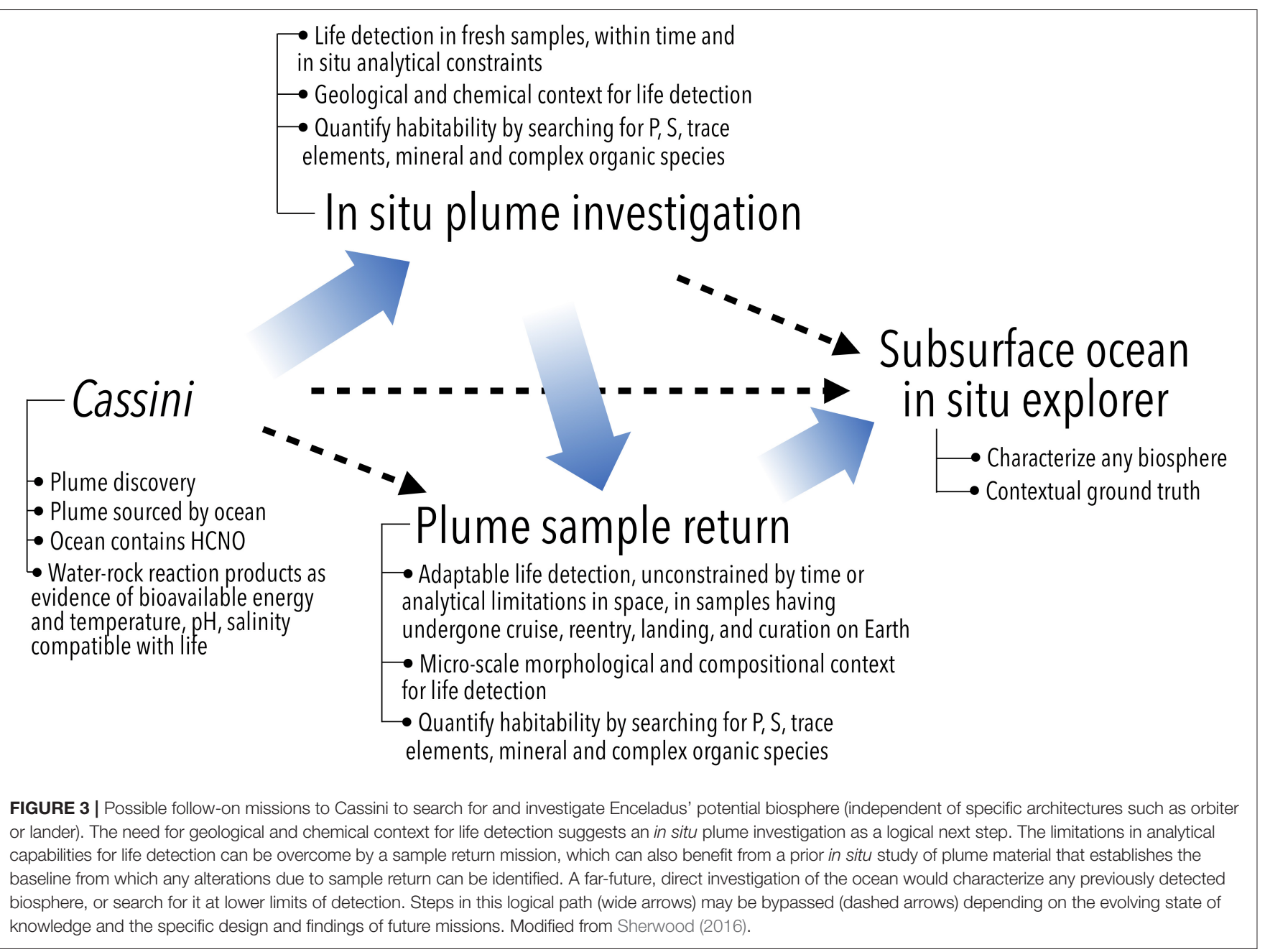

- Enantiomeric excess of all chiral amino acids (excesses of right-handedness, opposite to that observed in terrestrial biology, would exclude Earth contamination)

- Enantiomeric excess of all chiral sugar compounds (polyols)

- Patterns in the distribution of carbon chain length in long-chain hydrocarbons (e.g., periodic pattern of higher abundance as evidence of synthesis in cyclic reactions, or higher abundances for a specific range of chain lengths)

- Polymers with a repeating charge in their backbone

- Polymers of sugars, amino acids, or nucleobases

- Morphologies resembling microbial cells co-located with physical activity, chemical activity, or textures or compositions distinct from the environmental background

- Distribution of the number of types of operations needed to obtain each molecule in the pool of organic compounds [e.g., Pathway Complexity Index (Marshall et al., 2017)].

as well as material resulting from the impact of living organisms on their environment such as:

- Isotopic depletions in $\mathrm{D},{ }^{13} \mathrm{C}$ and ${ }^{15} \mathrm{~N}$ in organic compounds relative to inorganic matter (and in inorganic species relative to one another) that could be attributed to kinetic effects during biological reactions

- Co-located oxidants and reductants

- Inventory of chemical and mineral species that differs from that resulting from abiotic thermodynamic equilibrium or kinetic steady state.

Here, we have excluded signatures associated with the activity of organisms that are alive (e.g., motion or accumulation of metabolic products). Organisms in Enceladus' ocean would be highly unlikely to survive ejection to space, sample capture, exposure to radiation during the back cruise, Earth reentry, and/or any exposure to the relatively oxidizing conditions of Earth's surface (see Figure 4). These signatures may be targeted by in situ investigations if a fraction of organisms survives ejection to space and sample capture (e.g., Cosciotti et al., 2019).

Targeting multiple attributes is crucial to increase confidence in the life detection outcome. Previous experience has set the bar that all abiotic or contamination interpretations of the ensemble of life detection measurements must be deemed improbable enough in order to conclude that indigenous life has been 


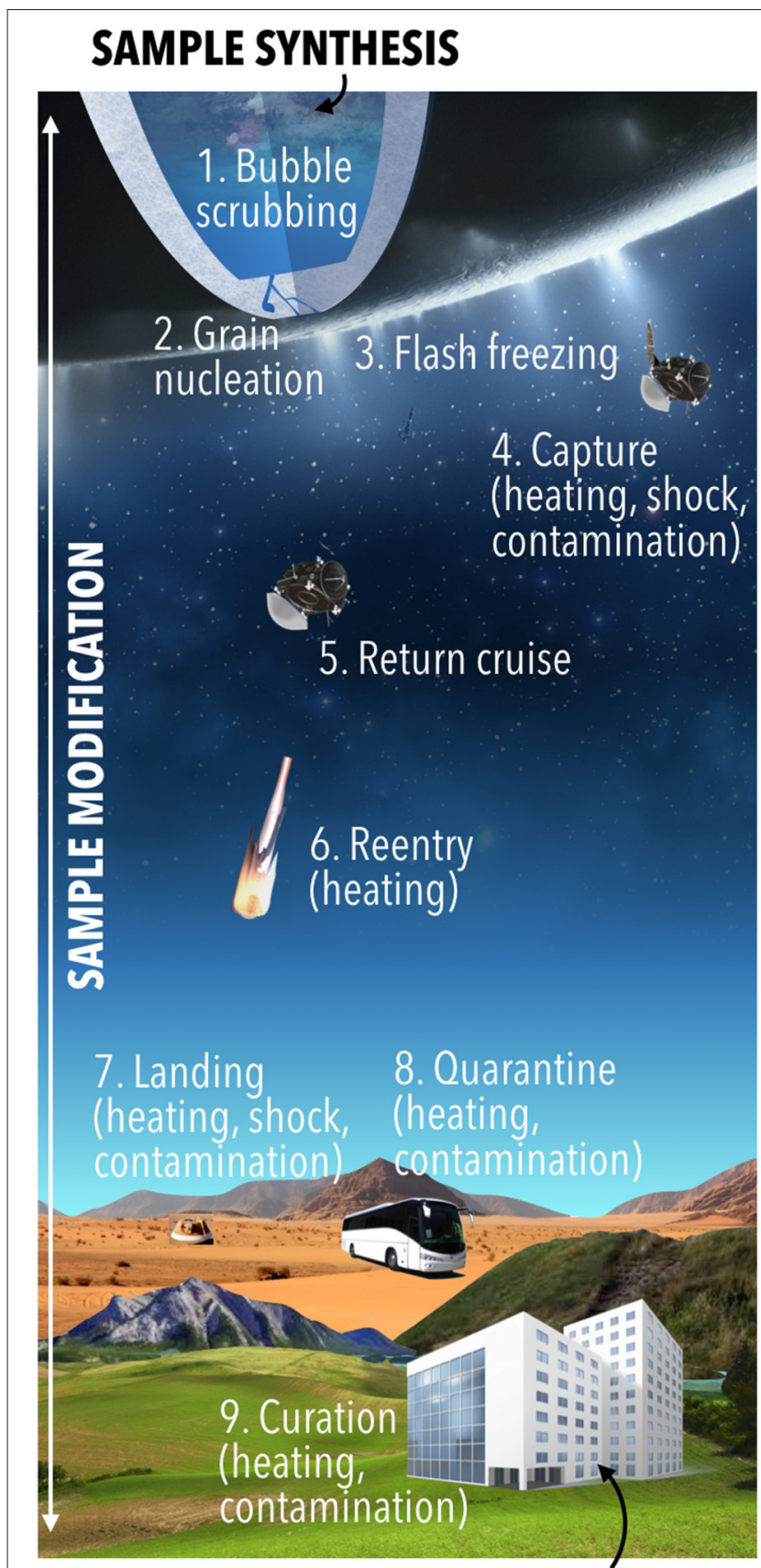

SAMPLE MEASUREMENT

FIGURE 4 | Stages of sample alteration between synthesis and measurement. This includes alteration steps due to ascent and ejection, which cannot be controlled, and steps from collection onward, for which sample alteration can be minimized. The sample can be further altered by the measurement method. Elements of this image from NASA-JPL/Caltech (public domain) and PNGImg, used under a CC BY-NC 4.0 license.

found. If life is not detected, a comprehensive set of chemical and morphological measurements is essential for determining how far toward life chemistry has progressed, reconstructing the sample's journey between synthesis and collection, and
TABLE 2 | Expected major constituents of Enceladus plume samples based on the evidence discussed in section "Evidence That Enceladus Is Habitable."

\begin{tabular}{|c|c|}
\hline Species & Abundance ( $\%$ by mass) \\
\hline \multicolumn{2}{|c|}{$\begin{array}{l}\left.\text { Plume solids }{ }^{\mathrm{a}} \text { (particles } \approx 0.2-2.0 \mu \mathrm{m} \text { at altitudes } \approx 25 \mathrm{~km}\right)(1-10 \text { mass } \% \\
\left.\text { of plume at altitudes } 20-30 \mathrm{~km}, 0.1-1 \% \text { at } 100 \mathrm{~km}^{\mathrm{b}}\right)\end{array}$} \\
\hline $\mathrm{H}_{2} \mathrm{O}$ ice $e^{\mathrm{c}, \mathrm{d}}$ & $\approx 99$ \\
\hline $\begin{array}{l}\mathrm{NaCl}, \mathrm{NaHCO} \\
\mathrm{KHCO}_{3}, \mathrm{Ka}_{2} \mathrm{CO}_{3} \text { salts }^{\mathrm{d}}\end{array}$ & $0.5-2$ \\
\hline $\mathrm{SiO}_{2}^{\mathrm{e}}$ & $<0.015$ to $<0.35^{f}$ \\
\hline $\begin{array}{l}\text { Unsaturated organic compounds with } \\
\text { mass }>200 \text { amug }^{g}\end{array}$ & $\sim 0.03$ \\
\hline $\begin{array}{l}\text { Mg-rich, Al-poor silicates with } \\
\text { possible but undetected } \mathrm{Fe}^{\mathrm{c}}\end{array}$ & $\sim 0.01$ \\
\hline $\begin{array}{l}\text { Low-mass, } \mathrm{N} \text { - and O-bearing, } \\
\text { soluble, volatile organic compounds }{ }^{\mathrm{h}}\end{array}$ & $\sim 0.0001-0.001$ \\
\hline \multicolumn{2}{|c|}{$\begin{array}{l}\text { Plume vapor }(90-99 \% \text { of plume by mass at altitudes } 20-30 \mathrm{~km} ; 99-99.9 \% \\
\text { at } 100 \mathrm{~km}^{\mathrm{b}} \text { ) }\end{array}$} \\
\hline $\mathrm{H}_{2} \mathrm{O}$ & 96-99 \\
\hline $\mathrm{CO}_{2}$ & $0.7-2$ \\
\hline $\mathrm{NH}_{3}$ & $0.4-1.2$ \\
\hline $\mathrm{CH}_{4}$ & $0.1-0.25$ \\
\hline $\mathrm{H}_{2}$ & $0.04-0.15$ \\
\hline $\begin{array}{l}\text { Organic compounds with } 2-6 \mathrm{C} \\
\text { atoms, some bearing } \mathrm{N} \text { and/or } \mathrm{O}^{f}\end{array}$ & $\sim 0.02^{j}$ \\
\hline
\end{tabular}

Percentages by mass are bookkept separately for solids and vapor. Notes and references: a Based on number percentages reported in $c, d$, and $k$ below and synthesized by Cable et al. (2020). ${ }^{b}$ Hedman et al. (2018). ${ }^{c}$ Postberg et al. (2008). ${ }^{d}$ Postberg et al. (2011). ${ }^{e} \mathrm{Hsu}$ et al. (2015). ${ }^{f}$ Postberg et al. (2018b). ${ }^{g}$ Postberg et al. (2018a). "h Khawaja et al. (2019). ${ }^{i}$ Converted to mass\% from vol\% given by Waite et al. (2017). ${ }^{j}$ Converted to mass\% from vol\% given by Waite et al. (2009). ${ }^{k}$ Postberg et al. (2009).

quantifying how much biomass (if any) should have been expected in the sample. Each attribute must be understood in the context of its provenance, because attributes can be altered or destroyed between their synthesis and their measurement. Provenance can be established via the same measurements that target the above attributes but generally requires additional contextual measurements, especially at the time and place of sample collection.

On returned samples, all of the above attributes can be measured by multiple techniques and independent teams at scales ranging from the full sample to individual atoms or molecules. An estimate of the composition of the plume samples, based on the results discussed in section "Evidence That Enceladus Is Habitable," is provided in Table 2. Example life detection techniques and corresponding amounts of sample needed are provided in Table 3. Notably, these measurements can address more than the driving question of life detection. For example, isotopic measurements could ascertain the origin of Enceladus or the materials it accreted (Sekine et al., 2014). More generally, these measurements would establish how far prebiotic chemistry has progressed inside Enceladus and quantify its habitability, thereby ensuring meaningful results even in the case of negative life detection.

As illustrated in Table 3, some measurements can only be done on Earth, such as those that provide contextual information at the smallest scales (e.g., compositions 
TABLE 3 | Life detection capabilities on returned samples (composition described in Table 2) compared to in situ, example options for implementation, and corresponding indicative amount of sample needed.

Measurement Example technique Capability on Earth $\quad$ Capability in situ

Over-representation of amino acids with high molecular mass and with structural isomeric

preference

Enantiomeric excess in all chiral amino acids

\section{Enantiomeric excess in all \\ chiral sugar compounds}

(polyols)

Distribution of carbon chain

electrophoresis, gas or

liquid chromatography)

Polymers with a repeating charge Nanopore sequencing

in their backbone

\section{Polymers of sugars, amino Immunoassa}

acids, or nucleotides

Metrix assistedaser desoption/ionization mass spectrometry (MALDI)

\section{Morphologies resembling}

microbial cells co-located with

physical activity, textures, or

compositions distinct from th

environmental background

Atomic force microscopy

\section{Optical microscopy}

Digital holographic microscopy

(Matrix-assisted) laser desorption ionization imaging mass spectrometry

Atom probe tomography; secondary ion mass spectrometry; scanning electron microscopy with X-ray spectroscopy (primarily $\mathrm{H}_{2} \mathrm{O}$, see Table 2)

\section{Capability on Earth}

Capability in situ

Quantify relative molar abundances of Quantify relative molar abundances of $\begin{array}{ll}\text { amino acids of mass } \leq 500 \text { amu present } & \text { amino acids of mass } \leq 500 \text { amu present } \\ \text { at }>1 \mathrm{pmol} \mathrm{g}^{-1} \text { at } \leq 20 \% \text { accuracy } 1 & \text { at } \geq 1 \mathrm{pmol} \mathrm{g}^{-1} \text { at } \leq 20 \% \text { accuracy }(1 \mathrm{re}\end{array}$ relative standard deviation)

As above, plus quantify molar

abundances of enantiomers of amino acids with up to 7 carbon atoms relative to glycine with $\leq 2 \%$ accuracy, quantify enantiomeric excess with $\leq 5 \%$ accuracy in amino acids present at $\mathbf{p p b}$ levels $\mathbf{s}^{\mathrm{c}, \mathrm{d}}$

Quantify relative molar abundances of enantiomers of sugar
to 6 carbon atoms
d,h

Quantify relative abundances of

long-chain hydrocarbons with mass $\leq$

$10^{4}$ amu present at $\geq 1 \mathrm{pmol} \mathrm{g}^{-1}$ at $20 \%$ present at $\geq 1 \mathrm{pmol} \mathrm{g}^{-1}$ at $20 \%$ accuracy

accuracy (1 rel. std. dev.)

$0.1 \mathrm{~g}(\text { in situ })^{\mathrm{b}}$

std. dev. $)^{a, b}$

As above, plus quantify molar abundances $0.5 \mathrm{mg}$ (sample return) ${ }^{\mathrm{f}, \mathrm{g}}$

of enantiomers of amino acids relative to $0.5 \mathrm{~g}$ (in situ) $)^{\mathrm{b}, \mathrm{g}}$

glycine with $\leq 2 \%$ accuracy, quantify

enantiomeric excess with $\leq 20 \%$ accuracy

Cannot currently be implemented ${ }^{d}$

mg to $g$ (sample return) $)^{\text {,i }}$

Identify and sequence DNA, RNA, and Not yet fully established.m

potentially other biopolymers without prio

detailed knowledge of their chemistryj,

starting from $\geq 1 \mathrm{ng}$ of polymer

Identify specific compounds present Identify specific compounds present at

at $10^{-18}-10^{-12} \mathrm{~g} \mathrm{~g}^{-1} \mathrm{p}$

$>0.1-1 \mu^{-1} g^{-1}$ (developed for flighta)

$>1 \mathrm{~kg}$ based on $100 \mathrm{ng}$ DNA (kg Earth ocean water $)^{-1} \mathrm{n}$. Enceladus biomass may be $10^{2}$ to $10^{10}$ times more dilute $\left(5 \times 10^{-6}-500 \text { cells g }{ }^{-1}\right)^{\circ}$

$>1 \mathrm{mg}$ (sample return); >1-10 g (in situ), assuming 100 cells $\mathrm{g}^{-1} \circ$ and 25 fg protein $\mathrm{cell}^{-1}$

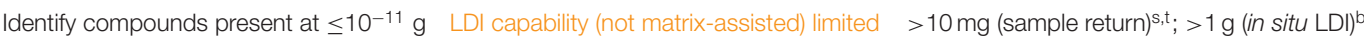
$\mu \mathrm{m}^{-2 \mathrm{~s}}$, requires preconcentration from to sub-1,000 amu range $(<10-\mathrm{mer})$. based on laser spot sizes.

$>10 \mathrm{mg}$ (for 100 cells $\mathrm{g}^{-1}$, i.e., $\sim 1 \mathrm{ng} \quad$ Sensitivity $1 \mathrm{ng} \mathrm{g}^{-1}$, requires protein $\mathrm{g}^{-1}$ ). Image their distribution at preconcentration from $1 \mathrm{~g}$

$\mu \mathrm{m}$-resolution ${ }^{t}$

Image atom by atom, perform force spectroscopy

Image at nm-scale resolution, with $\mu \mathrm{m}$-scale field of view ${ }^{u}$. Force

spectroscopya not yet developedv

$>1 \mathrm{~g}$ (assuming 100 cells $\mathrm{g}^{-1}$ )

Image at $\mu \mathrm{m}$-scale resolution, $0.5 \mathrm{~mm}$ field of view. Fluorescence with UV light source

No motility measurements possible (no live cells)

Map organic composition of and surrounding particles at $\mu \mathrm{m}$ scales for compound masses up to $10^{4}-10^{5} \mathrm{amu}^{\mathrm{t}}$

Map elemental composition of and

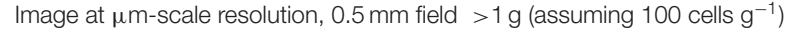
of view. Fluorescence with UV light source $e^{a, w, x}$

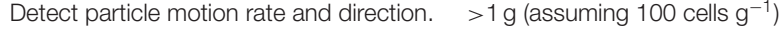
Developed for flight with spatial resolution

$\sim 1 \mu \mathrm{m}$, field of view $\sim 0.5 \mathrm{~mm}^{\times}$

No mapping capability

$<1 \mathrm{ng}$ (sub-mm grains)

surrounding non-icy microscopic particles

from $\mu \mathrm{m}$ to sub-nm scales ${ }^{y, z}$ 
Measurement types of operations needed to

obtain each molecule in the poo

of detected organic compounds

\section{Isotopic fractionation in}

organic compounds and

inorganic species

Co-located oxidants and

reductants species that differ from that

resulting from abiotic thermo

dynamic equilibrium or kinetic

steady state ${ }^{a g}$ e.g., Blake et al. (2012).

\section{Example technique}

[Nanoscale-] secondary ion mass

spectrometry

Mass spectrometry with separation stag

(e.g., capillary electrophoresis,

chromatography)

Orbitrap mass spectrometry

Wet chemistry + Gas

chromatography-isotope ratio mass

spectrometry (GC-IRMS)

Inductively coupled plasma mass

spectrometry

Secondary ion mass spectrometry

X-ray diffractometry

IR/Raman spectroscopy

Imaging mass spectrometry

$\alpha$-particle X-ray spectrometry

Laser-induced breakdown spectroscopy

Capability on Earth

Capability in situ

Indicative amount of needed plume material (primarily $\mathrm{H}_{2} \mathrm{O}$, see Table 2)

Map isotopic composition of and

surrounding microscopic particles ${ }^{2}$

Identify organic compounds of mass $\leq$
$10^{4}$ amu present at $\geq \mathbf{1} \mathrm{fmol} \mathrm{g}^{-1}$ and

mass resolution $>10^{5}-10^{6}$

Quantify compound-specific isotopic

${ }^{13} \mathrm{C} /{ }^{12} \mathrm{C},{ }^{15} \mathrm{~N} /{ }^{14} \mathrm{~N}$, and ${ }^{34} \mathrm{~S} /{ }^{32} \mathrm{~S}$ ratios ${ }^{\text {ab }}$

organic compounds present at $\geq 0.1$

$\mu \mathrm{mol} \mathrm{g}{ }^{-1}$. Deviations at $<5 \%$ precision

relative to plume $\mathrm{N}_{2}, \mathrm{CO}_{2}, \mathrm{H}_{2} \mathrm{~S}$

Quantify bulk isotopic ratios as above,

plus ${ }^{54} \mathrm{Fe} /{ }^{56} \mathrm{Fe}$ at $0.1 \%$ precision in

refractory plume material as a function of

bulk Fe abundance ae

Map organic (including macro-molecules) Map organic and inorganic species with

and inorganic species with masses up to masses up to at least $500 \mathrm{amu}^{\mathrm{a}}$ at scales

$10^{4}-10^{5}$ amu down to diffraction limit down to sub-mm. Inventory minerals

( $\mu \mathrm{m}$ to $\mathbf{n m}$-scale). Inventory minerals at present in the sample at bulk abundance

bulk abundance $>5$ vol\%. Ascertain $>5$ vol\%

organic and mineral crystal

structures

Same as Distribution of the number of types of operations needed to obtain each molecule in the pool of detected organic compounds and Co-located oxidants and reductants

Inventory of chemical and mineral

Sample amounts are subject to uncertainties on the size of a biosphere that Enceladus can support (section "Evidence That Enceladus Is Habitable").

Red: no capability; orange: capability under development; bold: measurements for which capabilities on Earth exceed those in situ by orders of magnitude. References: a Hand et al. (2017). ${ }^{b}$ Goesmann et al. (2017). cKoga and Naraoka

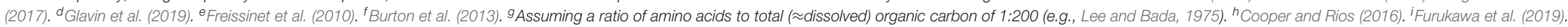
${ }^{j}$ Rezzonico (2014). ${ }^{k}$ Plesivkova et al. (2019). 'Carr et al. (2013). ${ }^{m}$ Sutton et al. (2019). ${ }^{n}$ Collins et al. (2018). ${ }^{\circ}$ Cable et al. (2020). ${ }^{p}$ Zhang et al. (2013). ${ }^{9}$ Parro et al. (2011). ${ }^{r}$ Zubkov et al. (1999). ${ }^{s}$ Cornett et al. (2007). ${ }^{t}$ Guenther et al.

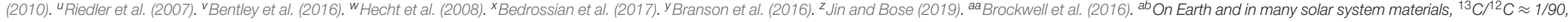
${ }^{15} \mathrm{~N}^{14} \mathrm{~N} \approx 1 / 270$ and ${ }^{34} \mathrm{~S} / 32 \mathrm{~S} \approx 1 / 20$ so expected amounts of the compounds with the rarer isotope are about as many times lower than their bulk abundances. For a given instrument limit of detection $\mathrm{O}$ and $\mathrm{H}$ isotopic measurements

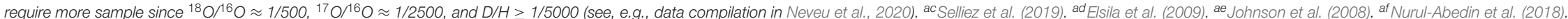


surrounding potential cells). Other measurements are much more informative if carried out on Earth, such as determining the isotopic composition of the bulk and various subsets of the organic material to infer the pathways involved in forming these compounds. For the rest of the measurements, such as broad characterization of organic compound classes or detection of cell morphologies, there is no advantage in returning samples because either flight instruments are sensitive enough or the limiting factor in the sample needed is the size of cells, not analytical capabilities.

Regarding morphological measurements, the survival of the integrity of ice-encased microbial cells to ejection (and sampling) is largely an open question. Cells have been found to survive freezing in salty water (e.g., Cosciotti et al., 2019). The structural integrity of a few percent of E. coli cells in aqueous medium was found to be preserved through injection into vacuum simulating eruption into Enceladus plumes (Bywaters et al., 2020). If sample amounts allow, it may be worth considering fixing part of the samples with agents such as glycerol, methanol, or paraformaldehyde, as commonly done in aqueous samples on Earth to better preserve microbial constituents for later analysis. However, this would involve a presupposition of the composition of potential Enceladus microorganisms.

The sample amounts provided in Table 3 are indicative as they hinge on the expected abundance of the targeted compound classes or cells in icy plume material. For some measurements, such as the distribution of the number of types of operations needed to obtain each molecule in the pool of detected organic compounds, the amount of sample needed is relatively well constrained by the sub-percent bulk organic content of plume vapor and grains (Table 2). However, for most, there are orderof-magnitude uncertainties arising from the size of the biosphere that could be supported. Here, we have assumed the same 100 cells $\mathrm{mL}^{-1}$ value (about 100 cells $\mathrm{g}^{-1}$ of ocean water) adopted by the Europa Lander Science Definition Team (Hand et al., 2017), based on comparison with analogous environments on Earth. This is near the upper end of the range provided in section "Energy Supply Limitation."

Nonetheless, the significantly lesser need for sample with Earth-based analyses may enable comprehensive life detection with a drastically reduced collection time. From Table 3 and other studies (Hand et al., 2017; MacKenzie et al., 2020), the sample needed for in situ analyses is several (a few but probably $<10$ ) grams. This excludes the nanopore measurement and assumes that each measurement is repeated in order to capture heterogeneity in the sample and in the analytical approach (e.g., 10 repeats; Lorenz, 2019). In contrast, only milligrams may be needed for life detection in returned samples owing to the capabilities of techniques such as (imaging-)MALDImass spectrometry and immunoassays. (Although for some measurements such as compound-specific isotopic analyses, a few orders of magnitude more sample enables measurements on a much broader set of compounds and isotope systems, providing a major improvement in understanding synthesis pathways.) Because a $1 \mathrm{~m}^{2}$ area flown through the plume at $50 \mathrm{~km}$ altitude is expected to collect on the order of $3 \mathrm{mg}$ (Porco et al., 2017), in situ analyses require hundreds of flybys by a Saturn or Enceladus orbiter or a landed mission, whereas one flyby may suffice for a sample return.

Even a $1 \mathrm{mg}$ sample comprises about $10^{9}$ micron-sized grains, such that known compositional heterogeneity across plume components (Postberg et al., 2009, 2011, 2018b; Hedman et al., 2018; Khawaja et al., 2019) would not statistically skew analyses.

The mass and state of samples that must be returned, dictated by the measurements to be carried out on Earth, in turn drive the choice of possible mission architectures. Architectures are also driven by the need to preserve the integrity of the targeted attributes (e.g., large organic compounds or microbial cells).

\section{POSSIBLE MISSION ARCHITECTURES}

The constants of an Enceladus sample return mission are the outbound and return legs between the Earth and the Saturn system. At Saturn, multiple options exist (Table 4). Similarly to in situ missions, sampling is much facilitated by Enceladus' low gravity (e.g., relative to Mars sample return). This allows for sampling of its extended plume through flybys (as explored by Tsou et al., 2012), hovering above the plumes, orbiting, or landing from orbit at a relatively low delta-velocity $(\Delta v)$ expense.

Here, we only discuss architectures for missions whose purpose is to collect samples, not perform in situ science. The mission architecture and associated sampling strategy and collector design are driven by three considerations: collecting enough sample for the desired analyses, minimizing changes to the sample upon collection, and minimizing contamination to the sample. We discuss the first two in this section and the third in section "Technical and Policy Considerations."

\section{Flying Through the Plume}

Samples can be collected in one or repeated passages through the plume. In order of complexity, architectures comprise a single fly-through on a Sun-orbiting ("free return") trajectory, a Saturn orbiter with Cassini-like fly-throughs steered by Titan gravity assists, and an Enceladus orbiter (Sekine et al., 2014). The traded quantities are mission duration, $\Delta \mathrm{v}$ (fuel mass, cost), and sampling velocity, whereas sampling altitude is set by navigation uncertainty in all cases. A sampling altitude typically considered is $50 \mathrm{~km}$ (e.g., Guzman et al., 2019), low enough that the plume density is high, yet high enough that material from the multiple venting locations at the surface have merged into a single plume.

Free return trajectories may lead to the longest missions. A heliocentric orbit with apoapsis at Saturn and periapsis at the Earth has a period of 34 years, more than twice the typical 15 -year duration for which spacecraft parts are qualified. That flight time can be reduced with maneuvers, gravity assists, and/or non-chemical propulsion; 25 years seems achievable even with chemical propulsion (Sekine et al., 2014). The sampling velocity for the latter trajectory was estimated at a few $\mathrm{km} \mathrm{s}^{-1}$ but could in principle be reduced by carefully balancing the relative heliocentric orbital velocities of Saturn and the slower spacecraft with Enceladus' orbital velocity around Saturn and the gravitational pull exerted by Saturn on the spacecraft. This approach only enables a single flyby, which may be sufficient to 
TABLE 4 | Architecture trades.

\begin{tabular}{|c|c|c|c|c|c|}
\hline & $\begin{array}{l}\text { Sun orbiter } \\
1 \text { flyby }\end{array}$ & $\begin{array}{l}\text { Saturn orbiter } \\
\approx 15 \text { flybys per Earth year }\end{array}$ & $\begin{array}{l}\text { Enceladus orbiter } \\
2 \text { flybys per Earth day }\end{array}$ & Catching lander & Scooping lander \\
\hline Collection rate & $\begin{array}{l}0.003 \mathrm{~g} \mathrm{~m}^{-2} \text { for the } \\
\text { whole mission }\end{array}$ & $0.045 \mathrm{~g} \mathrm{~m}^{-2}$ year $^{-1}$ & $2 \mathrm{~g} \mathrm{~m}^{-2}$ year $^{-1}$ & $\begin{array}{l}100 \mathrm{~g} \mathrm{~m}^{-2} \text { year }^{-1} \text { near } \\
\text { stripes, }>100 \text { times less } \\
\text { elsewhere in SPT, }<1,000 \\
\text { times less elsewhere }\end{array}$ & $3.5 \mathrm{~g} \mathrm{day}^{-1}$ \\
\hline Collection velocity & $\sim \mathrm{km} \mathrm{s}^{-1}$ & $\sim \mathrm{km} \mathrm{s}^{-1}$ & $\begin{array}{l}250 \mathrm{~m} \mathrm{~s}^{-1} \text { (vector sum of } \\
\text { orthogonal } 200 \mathrm{~m} \mathrm{~s}^{-1} \text { orbital } \\
\text { velocity and } 150 \mathrm{~m} \mathrm{~s}^{-1} \text { plume } \\
\text { particle velocity }{ }^{\mathrm{a}} \text {. }\end{array}$ & $\leq 150 \mathrm{~m} \mathrm{~s}^{-1 \mathrm{a}}$ & $\begin{array}{l}\text { Fallback at } \leq 150 \mathrm{~m} \mathrm{~s}^{-1} \\
\text { experienced by material }\end{array}$ \\
\hline Time since ejection & \multicolumn{3}{|c|}{$<5 \min \left(\leq 50 \mathrm{~km} / 0.15 \mathrm{~km} \mathrm{~s}^{-1}\right)$} & $<5-10 \min$ & $>10$ years \\
\hline $\begin{array}{l}\text { Access to negative } \\
\text { control } \\
\text { environment }^{b}\end{array}$ & No & \multicolumn{2}{|c|}{$\begin{array}{l}\text { Depends on contextual understanding of individual jet } \\
\text { sources }\end{array}$} & No (unless mobile) & $\begin{array}{l}\text { Limited by lander } \\
\text { reach/mobility }\end{array}$ \\
\hline $\begin{array}{l}\text { Rationale for } \\
\text { collection rate }\end{array}$ & \multicolumn{2}{|c|}{$3( \pm 2.5) \mathrm{mg} \mathrm{m}^{-2}$ per flyby at $50 \mathrm{~km}$ altitude ${ }^{a}$} & $\begin{array}{l}3( \pm 2.5) \mathrm{mg} \mathrm{m}^{-2} \text { per flyby at } \\
50 \mathrm{~km} \text { altitude }{ }^{\mathrm{a}} \text {. Orbital period } \\
\text { in halo orbit is } 12 \mathrm{~h}^{\mathrm{c}} \text { so } 6 \mathrm{mg} \\
\mathrm{m}^{-2} \text { day }^{-1} \text {. Plume density } \\
\approx 1.5 \mathrm{x} \text { higher at } 25 \mathrm{~km}^{-} \text {Figure } \\
4 \text { in ref. a), so } 9 \mathrm{mg} \mathrm{m}^{-2} \\
\text { day }^{-1} \text { at } 20-25 \mathrm{~km} \text {. }\end{array}$ & 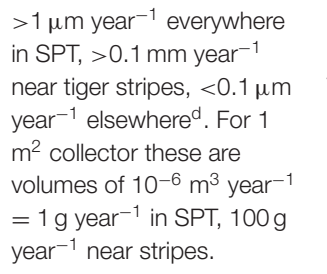 & $\begin{array}{l}7 \mathrm{~g} \text { per scoop, } 1 \text { scoop } \\
\text { every other daye } \\
\text { Time since ejection derived } \\
\text { assuming } 10 \mathrm{~cm}^{2} \text { scoop } \\
\text { and } 0.1 \mathrm{~mm}_{\text {year }}{ }^{-1} \\
\text { deposition rate. }\end{array}$ \\
\hline Mission $\Delta v$ & $\approx 0$ & $\sim 3 \mathrm{~km} \mathrm{~s}^{-1 \mathrm{f}}$ & $\begin{array}{l}\sim 4.5 \mathrm{~km} \mathrm{~s}^{-1} \text { (with all } \Delta \mathrm{v} \\
\text { budget in Saturn system from } \\
\text { ref. } \mathrm{f} \text { doubled) }\end{array}$ & \multicolumn{2}{|c|}{$\begin{array}{l}\sim 5 \mathrm{~km} \mathrm{~s}^{-1} \text { (Orbiter } \Delta \mathrm{v}+\approx 2 \times \Delta v \text { from/to halo orbit with } \\
\text { semimajor axis } 700 \mathrm{~km})^{\mathrm{c}, \mathrm{g}}\end{array}$} \\
\hline $\begin{array}{l}\text { Mission duration } \\
\text { (launch to reentry) }\end{array}$ & 25-34 years & $13-15$ years possible & & $\sim 26$ years & \\
\hline
\end{tabular}

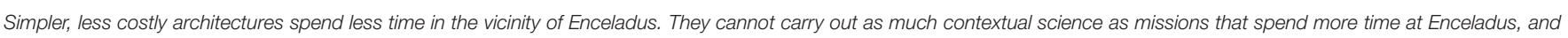

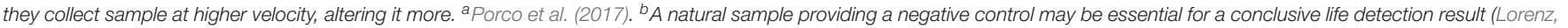
2019). ' Massarweh and Cappuccio (2020). ${ }^{d}$ Southworth et al. (2019). ${ }^{e}$ Hand et al. (2017). ${ }^{f}$ Tsou et al. (2012). 9 Spencer et al. (2010). SPT, South Polar Terrain.

achieve the life detection measurements of section "Measurement Strategy and Sample Needed," but with no contingency if the flyby circumstances prevent collection of enough sample. This risk and the long mission times make this approach not optimal compared to others described below.

Saturn-orbiting trajectories have been considered for Cassini follow-on, mid-sized in situ mission concepts (Lunine et al., 2015; Eigenbrode et al., 2018). Sample return mission times can be $<15$ years (Tsou et al., 2012; Sekine et al., 2014). Cassini operations have shown that repeated flybys are possible at a $\approx 3$-week cadence with assists from Saturn's largest moon Titan, allowing dozens of $\sim 2-4 \mathrm{~km} \mathrm{~s}^{-1}$ flybys within a collection time that remains short compared to the roundtrip time of $13+$ years (Tsou et al., 2012). Even upon collection at $\mathrm{km} \mathrm{s}^{-1}$, identifiable molecules up to small chains of monomers survive impact if encased in ice grains (Gu et al., 1999; Burchell et al., 2014) because much of the impact kinetic energy goes into the latent heat of sublimation of ice. Without ice encasing, even the simplest structures would not survive impact (Burchell and Harriss, 2019).

Enceladus-orbiting trajectories require prolonged pumpdown of the orbital velocity around Saturn via repeated flybys of Titan, Rhea, Dione, Tethys, and Enceladus itself in order to avoid consuming a prohibitive amount of propellant (Spencer et al., 2010; Sekine et al., 2014). Presumably, a similar amount of gravity assists would be needed to leave the Saturn system. An Enceladus orbiter study found a cruise time of 8.5 years, pump-down time of
3.5 years, and science phase of 1 year for a 13 -year in situ mission (Spencer et al., 2010). Sekine et al. (2014) found that coming back to Earth doubles the mission time to 26 years. The chief advantages to orbiting Enceladus are (1) the minimal fly-through velocity of just $200 \mathrm{~m} \mathrm{~s}^{-1}$ (Massarweh and Cappuccio, 2020), comparable to the velocities of plume particles, which minimizes changes to the sample upon collection, and (2) the high cadence of flybys relative to a Saturn orbit. Such a cadence may allow collection of enough material (grams) to sample microbial cells (Table 4). Due to Enceladus' low gravity and the proximity of massive Saturn, stable sampling orbits are halo orbits around the Saturn-Enceladus Lagrange 1 and 2 points, with a period of $\approx 12 \mathrm{~h}$ and an arbitrarily low sampling altitude (Massarweh and Cappuccio, 2020).

\section{Landed Sampling of Plume Material}

From Enceladus' surface, plume particles having fallen back at $\approx 150 \mathrm{~m} \mathrm{~s}^{-1}$ can be either caught just before reaching the surface (Porco et al., 2017) or scooped or otherwise retrieved as surface ice and snow (Hand et al., 2017; MacKenzie et al., 2020). In both cases, sample can be accumulated much faster than by flying through the plume (Table 4). The catching approach is still limited by the size of the collecting area but ensures collection of the freshest sample minutes after eruption. The south polar areas nearest the vent sites experience the highest deposition rates of order $0.1 \mathrm{~mm}_{\text {year }}{ }^{-1}$, i.e., $100 \mathrm{~g}_{\text {year }}{ }^{-1}$ for a $1 \mathrm{~m}^{2}$ collection area, 
with $\sim 1$ g year $^{-1} \mathrm{~m}^{-2}$ elsewhere in the south polar terrain and $<$ 1-100 $\mu$ g year $^{-1} \mathrm{~m}^{-2}$ farther north (Southworth et al., 2019).

In comparison, the scooping approach designed for a Europa lander concept can provide 1 to $10 \mathrm{~g} \mathrm{day}^{-1}$ (Hand et al., 2017). On Europa, this approach is necessary to get below the irradiated top surface layer, damaging to biosignatures, within week-tomonth mission lifespans limited by spacecraft radiation damage. Although the more benign radiation environment and freshly emplaced plume fallback do not warrant scooping on Enceladus, this approach enables a faster surface phase and/or return of more sample. The age (time since ejection) of a $1 \mathrm{~cm}^{3} \lesssim 1 \mathrm{~g}$ surface sample cube can be estimated as of order 10 years $\times$ (fallback rate $/ 0.1 \mathrm{~mm}_{\text {year }}{ }^{-1}$ ), since a cube of piled-up fallback $1 \mathrm{~cm}$ on a side would have $<1$ year-old material in its top $0.1 \mathrm{~mm}$ and 100 year-old material at the bottom if the fallback rate is $0.1 \mathrm{~mm}$ year $^{-1}$. Thus, surface sample ages could range from a few years old near vent sites where fallback rates are a few $0.1 \mathrm{~mm}^{\text {year }}{ }^{-1}$ and up to 1 million years old away from the south polar terrain (Southworth et al., 2019).

The complexity of a landed mission would be significantly increased relative to even an orbiter because of the need to consider forward planetary protection, communication with Earth never far above the horizon, and safe landing on a surface that is currently uncharacterized at the lander scale. However, the $\Delta \mathrm{v}$ difference between orbiting and landing is only $\approx 200 \mathrm{~m}$ $\mathrm{s}^{-1}$ owing to Enceladus' small surface gravity of $0.1 \mathrm{~m} \mathrm{~s}^{-2}, 1 \%$ of Earth's. Therefore, the need for added fuel relative to an orbiter is low. This and relatively fast surface sample collection suggest a mission duration similar to an orbiter, about 25 years. Thus, for a non-instrumented mission whose sole purpose is to collect samples for return, the trade between orbiting and landing is mainly driven by the amount of sample that can be collected in a given time vs. spacecraft complexity (e.g., to mitigate the risk of landing on rough terrain), with collection speeds and $\Delta \mathrm{v}$ being relatively similar. The sample amount that can be collected is on the order of kilograms (Table 4), enabling, e.g., $\mathrm{C}, \mathrm{N}, \mathrm{S}, \mathrm{O}$ and even $\mathrm{H}$ isotopic analyses of specific organic compounds present at sub-ppb abundances (Table 3). These are the abundances of many organic compounds identified in carbonaceous chondrites (Pizzarello et al., 2001; Sephton, 2002) whose bulk organic content is similar to that of Enceladus' plume (Alexander et al., 2007).

\section{TECHNICAL AND POLICY CONSIDERATIONS}

Returning samples from the outer Solar System presents several technical challenges that must be overcome for such a mission to succeed. Aside from potentially long mission durations, these include minimizing alterations to the sample between capture and measurement (Lakew et al., 2017; Treiman, 2017), a challenge shared in part with comet surface sample return; and implementation of planetary protection policy (McKay et al., 2014), a challenge shared with Mars sample return. Below, we discuss the aspects of these challenges that are intrinsic to plume sample return.

\section{Minimizing Sample Alteration Between Capture and Measurement}

Determining whether the returned samples were synthesized biologically or abiotically with enough confidence requires understanding the samples' state at the time of analysis and how they may have been altered since their synthesis. Example alteration processes are shown in Figure 4. They include natural processes between synthesis and capture (\#1-3 in Figure 4) such as:

- Bubble scrubbing in which bubbles of exsolved gases collect overlying organic material as they rise, selectively enriching the plume with compound classes that better bind to the bubble's surface (Porco et al., 2017);

- Interactions with ascent conduits such as condensation on cold walls or at bottlenecks where pressure is increased (Khawaja et al., 2019);

- Formation of a buoyant film of hydrophobic organic compounds at the top of the water table (Postberg et al., 2018a);

- Nucleation of grains around ejected salt and organic particles (Khawaja et al., 2019);

- Flash freezing of ocean water droplets whose outer layers vaporize into vacuum, cooling the rest (e.g., Glein and Waite, 2020).

These natural processes require a contextual understanding of the ascent and ejection processes (section "Sample Return: Advantages and Challenges"), such as the nature and shape of the conduits between the ocean and the surface.

Sample alteration processes also occur in (post-)capture environments that can be controlled (\#4-9), as discussed below. Steps \#5-9, i.e., the back cruise, reentry, landing, quarantine, and curation, are germane to sample return.

\section{Collector Design}

The Enceladus plume contains water and other volatile species, silicate grains, organic compounds of sizes ranging between tens and (at least) thousands of amu, and noble gases (Table 2). Each of these components may require a specific collection strategy. Below we focus primarily on organic molecules and silicate particles targeted by the life detection measurements of Table 3 .

Among collector materials, low-density silica aerogel has the ability, proven in flight (Stardust mission), to capture at $\mathrm{km} \mathrm{s}^{-1}$ velocity and preserve silicate grains and organic compounds as volatile as amino acids and amines (Tsou et al., 2003; Sandford et al., 2006; Glavin et al., 2008). Unfortunately, silica aerogel is also prone to capturing and retaining organic contaminants, which are difficult to exclude upon retrieval and concentration of sample particles dispersed in the aerogel matrix. Stardust sample investigations were complicated by a high background of terrestrial carbon ( $\mathrm{Si}-\mathrm{CH}_{3}$ groups), including small organic compounds used in biology, within the aerogel itself (Elsila et al., 2009). Aerogel is intrinsically a high-background material due to its large internal surface area, which determines the abundance of atmospheric contaminants on any material, and which is increased when decreasing aerogel density to minimize 

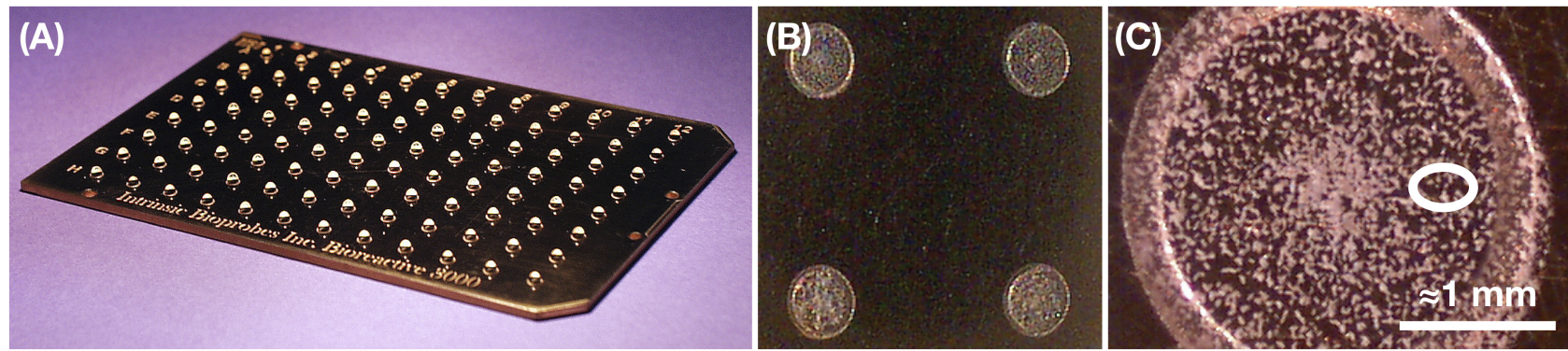

FIGURE 5 | Example possible patterned secondary collector surface that could be robotically inserted into analytical instruments on Earth (here, a MALDI mass spectrometer; see Table $\mathbf{3})$. (A,B) This metal surface comprises $8 \times 12$ hydrophilic spots, each 2-3 mm in diameter. Sample accumulated on the plate can be concentrated for analysis by depositing droplets (here, of laser ablation matrix, i.e., a solution of small molecules absorbing at the laser wavelength) and letting dry prior to insertion into the mass spectrometer. These steps can be carried out robotically so as to minimize exposure to Earth's biosphere and human contamination. (C) Close-up of a spot, with a typical laser spot size depicted by a white oval. Credit: Intrinsic Bioprobes Inc. (now part of Thermo Fisher Scientific).

capture damage. Moreover, the recovery of trapped samples is difficult, because aerogel is typically hydrophobic and cannot be heated to temperatures high enough to completely remove organic compounds without damaging the aerogel structure, resulting again in high background levels.

Other substrates considered for capturing refractory particles are metal (e.g., aluminum, gold, stainless steel, or titanium) surfaces. Materials with high depth to cross-section ratios, such as honeycomb, should be easier to outgas. Stacks of thin metal foils can likewise capture particles relatively gently but share with aerogel the difficulty of extracting the sample from the matrix.

On single solid metallic surface collectors, organic contamination is even more easily removed either chemically or thermally. On such solid surfaces, ice grains are vaporized upon impact. This frees relatively intact ice-encased organic or inorganic compounds (Burchell et al., 2014) since most of the impact kinetic energy is converted into latent heat of sublimation of the ice. Retaining these compounds requires deposition on secondary collector surfaces (Aksyonov and Williams, 2001) that could be kept cold or electrically charged to also retain volatile and/or ionic species. Such secondary collectors present analytical advantages. They could be configured for direct, robotic insertion into analytical instruments upon return, minimizing exposure to terrestrial contaminants. They could also be patterned so that the diffuse layer of captured material can be dissolved and concentrated into small spots prior to analysis (Figure 5).

\section{Means to Check That Enough Sample Has Been Collected}

A "go/no go" decision to undertake the return leg is likely to involve a check that enough sample has been collected. This could be achieved by microscopic imaging of the collector (if the geometry allows) or of a witness plate. One could envision a set-up similar to the optical and/or atomic force microscopes onboard the Phoenix and Rosetta spacecrafts, tailored to the expected size and number density of collected particles (Bentley et al., 2016). Alternatively, one could measure the effect of a changing mass of the collection surfaces on the frequency of a quartz crystal microbalance. This technique is commonplace in monitoring chemical contamination (e.g., deposition of organic compounds outgassed from tapes or glues) during spacecraft assembly or even in flight (Dirri et al., 2019). If the collected mass is significant (e.g., landed collection), its effect on the collector or spacecraft inertia could be monitored. This was the approach taken for the OSIRIS-REx asteroid sample return mission designed to collect at least $60 \mathrm{~g}$ (Lauretta et al., 2017).

\section{Sample Preservation Through Return Cruise and Reentry}

The return cruise environment is largely unchanged from that of collection, save for the accumulation of radiation and a steadily increasing solar flux warming the return capsule. Radiation can be quantified and mitigated by shielding the capsule as necessary. Warming is an issue mostly for the preservation of compounds that sublimate at temperatures above the $\approx 60-70 \mathrm{~K}$ of icy surfaces at Saturn.

In contrast, most of the thermal and mechanical stresses to the sample occur at reentry and (potentially impact) landing (\#6-7 in Figure 4; Venkatapathy et al., 2017). The degree of stress mitigation (e.g., active collector cooling or phase change materials to minimize heating) depends on the sample: refractory particles can tolerate higher temperatures and gases tolerate mechanical stresses. Given these differences, it may be advantageous to separate refractory and volatile (including ice) sample fractions prior to reentry. This would prevent them from reacting with one another at increased temperatures and pressures experienced during reentry and would allow distinct strategies for mitigation of these conditions to a degree appropriate for each fraction. A possible implementation was developed for the CAESAR comet sample return mission concept (Glavin et al., 2018; Lunine et al., 2018). It involved warming the sample captured and contained in the return capsule to sublimate $\mathrm{H}_{2} \mathrm{O}$ and more volatile species. The vapors were passed into a gas reservoir also mounted in the return capsule and separate from the solid sample container. The gas reservoir was subsequently sealed while the solid sample container was vented to space until reentry, at which point its vent was closed to prevent contamination from Earth's atmosphere. 


\section{Minimizing and Characterizing Terrestrial Contamination}

The minimization and characterization of spacecraft particulate, molecular, and biological contributions from Earth environments prior to launch and from launch through sampling has been extensively documented in the context of the Mars 2020 astrobiology sample collection mission (Summons et al., 2014), as well as the OSIRIS-REx and Hayabusa missions (Dworkin et al., 2018; Uesugi et al., 2019). Fundamental contamination mitigation steps require cleaning the collector and return capsule and protecting them from recontamination. To help discriminate between plume material and terrestrial contamination, witness materials that share the properties of collector surfaces, such as composition and geometry, and exposed to the same environments as the collector except during plume sampling, could be included in the collector and capsule design. Collector backgrounds could be reduced by outgassing to space prior to sample capture, both by heating using the onboard power supply and by exposure to solar radiation.

During and after Earth return, the sample is subject to contamination inputs and to losses of the volatile components. For example, analyses of Stardust foils stored at room temperature in an ISO Class 5 cleanroom at NASA's Johnson Space Center revealed that the levels of amino acid glycine they contained dropped by a factor 6-10 over 1,000 days (Figure 6). This could be due to loss of volatile glycine precursors such as formaldehyde and aminoacetonitrile, as briefly discussed by Glavin et al. (2014). Mitigation approaches such as sealing (implemented for the Hayabusa-2 mission; Okazaki et al., 2017) and leak rate monitoring can address both contamination and losses. Other approaches can address one but have adverse effects on the other, complicating their implementation: for example, keeping the collector cold mitigates volatile loss, but makes it more effectively trap contamination from the atmosphere and (during reentry) products of ablation and outgassing of the return capsule. Nonetheless, it is likely that plume samples would require curation in a controlled environment emulating the cold vacuum conditions at the plume.

Contamination also occurs from any refractory material used to manipulate or store the sample, such as metal tools or vessels. This has previously resulted in investigation of a potential bias in the measured metal content in lunar samples (Day et al., 2018), although in that case the bias was found to be insignificant.

\section{Back Planetary Protection}

The purpose of back planetary protection is to prevent inadvertent contamination of the Earth with viable biological material indigenous to the sampled world and carried onboard the robotic spacecraft. A non-binding planetary protection policy by which all major space agencies abide is set by the international Committee on Space Research (COSPAR).

In the COSPAR policy (Kminek et al., 2017), back planetary protection policy is not implemented into quantitative requirements. This policy (Category V-Restricted Earth Return) and a proposed implementation (Takano et al., 2014) are further discussed below.

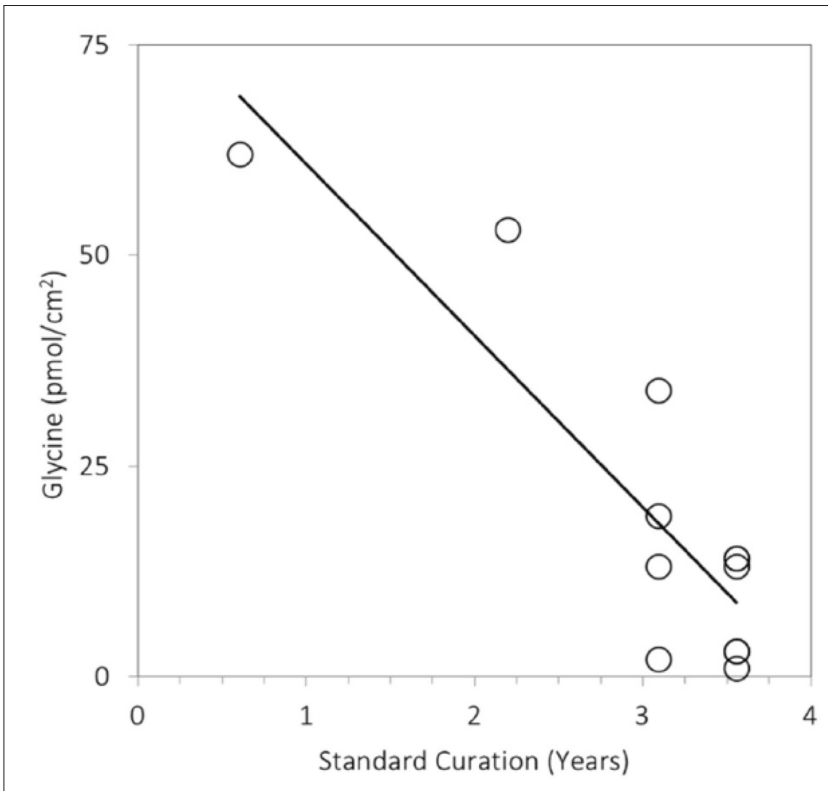

FIGURE 6 | Steady decline in the abundance of the amino acid glycine extracted from Stardust foils exposed to comet Wild 2 as a function of time in curation. The foils were stored at room temperature in an ISO Class 5 cleanroom at NASA's Johnson Space Center. Measurements were obtained using the methods described in Glavin et al. (2008) and Elsila et al. (2009).

The lack of quantitative back planetary protection requirements contrasts with forward planetary protection policy, which aims to prevent contamination of the sampling environment with viable Earth biology. The policy requires that the probability of a given mission introducing microbes into the ocean be lower than $10^{-4}$. It specifies that this probability be calculated from (at least) bioburden at launch, survival during the cruise and in the radiation environment adjacent to Enceladus, probability of encountering the surface, mechanisms and timescales of transport to a subsurface liquid water environment, and survival and proliferation before, during, and after subsurface transfer (Kminek et al., 2017).

The $10^{-4}$ threshold is arbitrary (National Research Council, 2012; Sherwood et al., 2019). Although some of the above factors are poorly known, there are possible estimation methods. Bioburden can be estimated with organic compound proxies (Summons et al., 2014). The radiation environment and its variations have been measured in interplanetary space and near Enceladus (Krupp et al., 2018). The microbial tolerance to radiation in interplanetary space has been modeled based on the results of irradiation experiments (Mileikowsky et al., 2000). Probabilities of surface impacts too can be modeled (Nicholson, 2009). Transport from the surface into the ocean by tectonic motions seems unlikely based on geophysical modeling (Howell and Pappalardo, 2019); however, infrequent fracturing (Hemingway et al., 2019) and burial under plume fallout (Southworth et al., 2019) point to million-year timescales of delivery to the ocean. Finally, compiled microbial growth rates indicate that at $273 \mathrm{~K}$, the turnover rate of organic carbon 
metabolized for biomass growth is about 1 mass\% per hour in near-surface environments on Earth (Price and Sowers, 2004). This rate could be much lower in energy-limited environments (Hoehler and Jørgensen, 2013).

As an alternative to the difficult quantification of the above factors, a binary decision tree has been proposed (National Research Council, 2012): Do current data indicate that the target body lacks (1) liquid water? (2) bioessential elements? (3) physical conditions in the range of extreme conditions for Earth life? (4) chemical energy? (5) complex organic nutrients? (6) Is the likelihood of contact with the habitable environment $<10^{-4}$ ? (7) Can treatment at $60^{\circ} \mathrm{C}$ for $5 \mathrm{~h}$ eliminate physiological groups that can propagate on the target body? If one or more of these decision points is evaluated negatively, the spacecraft must be heated above $110^{\circ} \mathrm{C}$ for $30 \mathrm{~h}$ for sterilization. This approach was implemented in categorizing the Hayabusa-2 mission as an Unrestricted Earth Return (Yano, 2017).

Both approaches enable quantitative requirements on which consensus can be reached, compliant designs made and evaluated, and their cost estimated. However, they do not allow projects to select or develop implementations best suited to meet their requirements (Stern et al., 2019). Instead, they draw on the contamination mitigation techniques of previous missions such as Viking. The contrary is true for back planetary protection of Cat. V-Restricted Earth Return missions, which lack a precedent (although one may be set by Mars sample return in the coming years). The lack of quantitative requirements provides flexibility in the implementation, but hampers preliminary designs, means to check compliance, and costing. Yet, the current level of scientific and technical understanding could allow for at least some level of further specification into quantitative requirements and means to evaluate whether these requirements are met. The Restricted Earth Return provisions are:

\footnotetext{
"Unless the samples to be returned from [...] Enceladus are subjected to an accepted and approved sterilization process, the canister(s) holding the samples returned from [...] Enceladus shall be closed, with an appropriate verification process, and the samples shall remain contained during all mission phases through transport to a receiving facility where it (they) can be opened under containment."
}

To implement this provision, a maximum allowable leakage rate could be specified for particles of a specific size, such as the size of the smallest known biological pathogens $(10-15 \mathrm{~nm}$ for prions; Silveira et al., 2005). This requirement should be met even for impact landing on Earth, whether intended or accidental, necessitating systems to monitor the capsule's integrity (e.g., temperature and pressure sensors). To test whether the leakage rate requirement is met, tracers of smaller size than the above particle size threshold could be emplaced in the contained areas and monitored outside these sealed areas. Helium, with a van der Waals radius of $0.14 \mathrm{~nm}$, is commonly used for leak detection, with leakage rates expressed in $\mathrm{Pa} \mathrm{m} \mathrm{m}^{3}$ of $\mathrm{He}$ (i.e., the He pressure decrease rate for a set volume) that are routinely measured using commercial devices (Younse et al., 2012). Despite its ease of measurement, the use of $\mathrm{He}$ as a tracer could place unnecessarily stringent constraints on systems that need only contain potential pathogens no less than 70 times larger. For this provision as for the others below, a possible first implementation in the context of Mars sample return could inform implementation for a sample return from Enceladus.

\begin{abstract}
"The mission and the spacecraft design must provide a method to 'break the chain of contact' with [...] Enceladus. No uncontained hardware that contacted material from [...] Enceladus or [its] plumes, shall be returned to the Earth's biosphere or the Moon. Isolation of such hardware from the [...] Enceladan environment shall be provided during sample container loading into the containment system, launch from [...] Enceladus, and any in-flight transfer operations required by the mission."
\end{abstract}

This provision could be met by requiring that uncontained spacecraft parts in contact with plume material either be jettisoned prior to or sterilized during Earth reentry (whether passively by ambient radiation or by an active sterilization process). Additionally, the policy could specify maximum allowable probabilities (which can be quantified during trajectory design) of impact of unconfined spacecraft parts on the Earth or the Moon or of microbial survival on such parts during reentry.

\begin{abstract}
"Reviews and approval of the continuation of the flight mission shall be required at three stages: (1) prior to launch from Earth; (2) subsequent to sample collection and prior to a maneuver to enter a biased Earth return trajectory; and (3) prior to commitment to Earth re-entry."
\end{abstract}

This requirement is specific and does not affect design or costing.

\begin{abstract}
"For unsterilized samples returned to Earth, a program of life detection and biohazard testing, or a proven sterilization process, shall be undertaken as an absolute precondition for the controlled distribution of any portion of the sample."
\end{abstract}

This could be interpreted as requiring specific programs of life detection and biohazard testing during one or several mission stages. In situ life detection with techniques such as those described in Table 3 has been proposed (Yano et al., 2016a). Life detection measurements could also be made non-invasively after recovery of the capsule on Earth but prior to opening the sealed container. This could be achieved either by designing the return capsule and sample container for non-contact measurements by outfitting them with optical waveguides or puncturable interfaces (Yano et al., 2016b), or by interrogating the capsule with noncontact techniques such as X-ray computed tomography (Takano et al., 2014; Zeigler et al., 2019). However, many of the techniques able to detect features of life require contact (Table 3). Life detection after opening the capsule, but prior to distributing the sample could be carried out onboard a research ship confined at sea in international waters (Takano et al., 2014). Much of the needed equipment (Summons et al., 2014; Table 3) is carried on existing research vessels (Takano et al., 2014). The planetary protection policy could specify which of the above stages are acceptable for life detection and biohazard testing. It could also list possible methods of sterilization. These include dry heat 
microbial reduction (Daspit et al., 1975), flash heating to $500^{\circ} \mathrm{C}$ (Heller et al., 2017; Voskuilen and Sakievich, 2017), hydrogen peroxide and/or nitrogen dioxide gases (Heller et al., 2017), and ionizing radiation (Yano et al., 2016b).

Designing and testing sample return architectures to these requirements could also include:

- Analyses of navigation errors to assess impact probabilities both on the target ocean world and in the Earth-Moon system;

- Design, building, and testing of sealing systems, including approaches to monitor seal integrity and sterilize uncontained spacecraft parts in the event of seal breech;

- Thermal modeling of spacecraft surfaces during Earth reentry.

The above examples are only possible approaches to implementing Cat. V-Restricted Earth Return policy. Providing this level of specification either in the policy itself or in vetted documentation (e.g., NASA, 2011 NASA Procedural Requirement $8020.12 \mathrm{D}$ that implements the COSPAR Policy), and specifying that other approaches may be accepted if it can be demonstrated that they equivalently achieve compliance, would facilitate formulation and costing of astrobiology sample return missions.

\section{CONCLUSIONS}

At Enceladus, plume material ejected minutes before from subsurface liquid reservoirs harboring the ingredients for life represents an ideal sample in which to search for life. In situ strategies measure sample properties in their freshest state, as well as essential context. Sample return provides the ability to adapt follow-on analyses to findings, access to the full diversity of existing and future interrogation techniques, and time to assess the validity of results. Sample return may also require substantially less sample than in situ investigations. This complementarity may be necessary for life detection (Sherwood, 2016). The ease of access of ocean material through the plume allows one to bypass the sequence of missions to "fly by, orbit, land, rove, and return samples." For sample return, a Saturn orbiter flying about ten times through Enceladus' plume minimizes the mission duration to $\approx 15$ years, but the effect of

\section{REFERENCES}

Aksyonov, S. A., and Williams, P. (2001). Impact desolvation of electrosprayed microdroplets-a new ionization method for mass spectrometry of large biomolecules. Rapid Commun. Mass Spectrometry 15, 2001-2006. doi: $10.1002 / \mathrm{rcm} .470$

Alexander, C. M. O.'D., Fogel, M., Yabuta, H. and Cody, G. D. (2007). The origin and evolution of chondrites recorded in the elemental and isotopic compositions of their macromolecular organic matter. Geochimica et Cosmochimica Acta. 71, 4380-4403. doi: 10.1016/j.gca.2007. 06.052

Arevalo, R., Selliez, L., Briois, C., Carrasco, N., Thirkell, L., Cherville, B., et al. (2018). An orbitrap-based laser desorption/ablation mass spectrometer designed for spaceflight. Rapid Commun. Mass Spectrometry 32, 1875-1886. doi: $10.1002 / \mathrm{rcm} .8244$ collection at $1 \mathrm{~km} \mathrm{~s}^{-1}$ or more must (and can) be minimized. Enabling technology developments are in the areas of sample collection and preservation, as well as in the implementation of Restricted Earth Return planetary protection policy for cold samples. Finally, many of the considerations discussed here could be applied to the exploration of other worlds showing hints of erupted material that could sample a subsurface ocean, such as Europa (Roth et al., 2014; Sparks et al., 2016), Ceres (Küppers et al., 2014; Ruesch et al., 2016), or Triton (Kirk et al., 1995).

\section{AUTHOR CONTRIBUTIONS}

MN wrote the first draft of the manuscript. All authors contributed to manuscript revision, read, and approved the submitted version.

\section{FUNDING}

MN acknowledges support from the Center for Research and Exploration in Space Sciences II Cooperative Agreement between NASA Goddard Space Flight Center and the University of Maryland, College Park (award number 80GSFC17M0002).

\section{ACKNOWLEDGMENTS}

We thank Kate Craft and Jonathan Lunine for insightful comments on a first draft of this manuscript. This manuscript also benefited from comments by two reviewers. Some of the material in this paper was previously contributed by DG at the 2014 International Workshop on Instrumentation for Planetary Missions (Greenbelt, MD, USA) [collection strategies]; by MN at the 2015 Workshop on the Potential for Finding Life in a Europa Plume (Moffett Field, CA, USA) [collection strategies], the 2017 Astrobiology Science Conference (Mesa, AZ, USA, April 2017) [planetary protection], the 42nd COSPAR Scientific Assembly (Pasadena, CA, USA, July 2018) [planetary protection]; and by HY in contributions to the canceled 41st COSPAR Scientific Assembly (Istanbul, Turkey) [sample analysis and planetary protection]. Jamie Elsila contributed to obtaining the data shown in Figure 6.

Baum, W. A., Kreidl, T., Westphal, J. A., Danielson, G. E., Seidelmann, P. K., Pascu, D., et al. (1981). Saturn's E ring: I. CCD observations of March 1980. Icarus 47, 84-96. doi: 10.1016/0019-1035(81)90093-2

Bedrossian, M., Lindensmith, C., and Nadeau, J. L. (2017). Digital holographic microscopy, a method for detection of microorganisms in plume samples from Enceladus and other icy worlds. Astrobiology 17, 913-925. doi: 10.1089 /ast.2016.1616

Bentley, M. S., Arends, H., Butler, B., Gavira, J., Jeszenszky, H., Mannel, T., et al. (2016). MIDAS: lessons learned from the first spaceborne atomic force microscope. Acta Astronautica 125, 11-21. doi: 10.1016/j.actaastro.201 6.01 .012

Blake, D., Vaniman, D., Achilles, C., Anderson, R., Bish, D., Bristow, T., et al. (2012). Characterization and calibration of the CheMin mineralogical instrument on Mars Science Laboratory. Space Sci. Rev. 170, 341-399. doi: 10.1007/s11214-012-9905-1 
Bouquet, A., Mousis, O., Waite, J. H., and Picaud, S. (2015). Possible evidence for a methane source in Enceladus' ocean. Geophys. Res. Lett. 42, 1334-1339. doi: 10.1002/2014GL063013

Branson, O., Bonnin, E. A., Perea, D. E., Spero, H. J., Zhu, Z., Winters, M., et al. (2016). Nanometer-scale chemistry of a calcite biomineralization template: implications for skeletal composition and nucleation. Proc. Natl. Acad. Sci. U.S.A. 113, 12934-12939. doi: 10.1073/pnas.1522 864113

Brockwell, T. G., Meech, K. J., Pickens, K., Waite, J. H., Miller, G., Roberts, J., et al. (2016). "The mass spectrometer for planetary exploration (MASPEX)," in 2016 IEEE Aerospace Conference (Big Sky, MT), 17. doi: 10.1109/AERO.2016.7500777

Burchell, M., and Harriss, K. (2019). Organic molecules: is it possible to distinguish aromatics from aliphatics collected by space missions in high speed impacts? Sci. 1:53. doi: 10.3390/sci1020053

Burchell, M. J. (2006). W (h) ither the Drake equation? Int. J. Astrobiol. 5, 243-250. doi: $10.1017 /$ S1473550406003107

Burchell, M. J., Bowden, S. A., Cole, M., Price, M. C., and Parnell, J. (2014). Survival of organic materials in hypervelocity impacts of ice on sand, ice, and water in the laboratory. Astrobiology 14, 473-485. doi: 10.1089/ast.2013.1007

Burton, A. S., Elsila, J. E., Hein, J. E., Glavin, D. P., and Dworkin, J. P. (2013). Extraterrestrial amino acids identified in metal-rich $\mathrm{CH}$ and $\mathrm{CB}$ carbonaceous chondrites from Antarctica. Meteoritics Planet. Sci. 48, 390-402. doi: 10.1111/maps.12063

Bywaters, K., Stoker, C. R., Do Nascimento, N. B. and Lemke, L. (2020). Towards determining biosignature retention in icy world plumes. Life 10:40. doi: 10.3390/life 10040040

Cable, M. L., Neveu, M., Hsu, H.-W., and Hoehler, T. M. (2020). "Enceladus," in Planetary Astrobiology, eds V. S. Meadows, G. Arney, B. Schmidt, and D. J. Des Marais (Tucson, AZ: University of Arizona Press), 217-246. doi: 10.2458/azu_uapress_9780816540068-ch009

Carr, C. E., Zuber, M. T., and Ruvkun, G. (2013). "Life detection with the Enceladus Orbiting Sequencer," in 2013 IEEE Aerospace Conference (Big Sky, MT), 12. doi: 10.1109/AERO.2013.6497129

Choblet, G., Tobie, G., Sotin, C., Běhounková, M., Cadek, O., Postberg, F., et al. (2017). Powering prolonged hydrothermal activity inside Enceladus. Nat. Astronomy 1, 841-847. doi: 10.1038/s41550-017-0289-8

Collins, R. A., Wangensteen, O. S., O’Gorman, E. J., Mariani, S., Sims, D. W., Genner, M. J., et al. (2018). Persistence of environmental DNA in marine systems. Commun. Biol. 1:185. doi: 10.1038/s42003-018-0192-6

Cooper, G., and Rios, A. C. (2016). Enantiomer excesses of rare and common sugar derivatives in carbonaceous chondrites. Proc. Natl. Acad. Sci. U.S.A. 113, E3322-E3331. doi: 10.1073/pnas.1603030113

Cornett, D. S., Reyzer, M. L., Chaurand, P., and Caprioli, R. M. (2007). MALDI imaging mass spectrometry: molecular snapshots of biochemical systems. Nat. Methods 4, 828-833. doi: 10.1038/nmeth1094

Cosciotti, B., Balbi, A., Ceccarelli, A., Fagliarone, C., Mattei, E., Lauro, S. E., et al. (2019). Survivability of anhydrobiotic cyanobacteria in salty ice: implications for the habitability of icy worlds. Life 9:86. doi: 10.3390/life9040086

Daspit, L. P., Stern, J. A., and Cortright, E. M. (1975). Viking heat sterilization-progress and problems. Acta Astronaut. 2, 649-666. doi: 10.1016/0094-5765(75)90007-7

Day, J. M., Maria-Benavides, J., McCubbin, F. M., and Zeigler, R. A. (2018). The potential for metal contamination during Apollo lunar sample curation. Meteoritics Planet. Sci. 53, 1283-1291. doi: 10.1111/maps.13074

Deamer, D., and Damer, B. (2017). Can life begin on Enceladus? A perspective from hydrothermal chemistry. Astrobiology 17, 834-839. doi: 10.1089/ast.2016.1610

Dirri, F., Palomba, E., Longobardo, A., Zampetti, E., Saggin, B., and Scaccabarozzi, D. (2019). A review of quartz crystal microbalances for space applications. Sens, Actuat. A Phys. 287, 48-75. doi: 10.1016/j.sna.2018.12.035

Dodd, M. S., Papineau, D., Grenne, T., Slack, J. F., Rittner, M., Pirajno, F., et al. (2017). Evidence for early life in Earth's oldest hydrothermal vent precipitates. Nature 543, 60-64. doi: 10.1038/nature21377

Dworkin, J. P., Adelman, L. A., Ajluni, T., Andronikov, A. V., Aponte, J. C., Bartels, A. E., et al. (2018). OSIRIS-REx contamination control strategy and implementation. Space Sci. Rev. 214:19. doi: 10.1007/s11214-0170439-4
Eigenbrode, J., Gold, R. E., McKay, C. P., Hurford, T., and Davila, A. (2018), "Searching for life in an ocean world: the Enceladus Life Signatures and Habitability (ELSAH) mission concept," in 42nd COSPAR Scientific Assembly (Pasadena, CA).

Elsila, J. E., Glavin, D. P., and Dworkin, J. P. (2009). Cometary glycine detected in samples returned by Stardust. Meteoritics Planet. Sci. 44, 1323-1330. doi: 10.1111/j.1945-5100.2009.tb01224.x

Feibelman, W. A. (1967). Concerning the “D” ring of Saturn. Nature 214, 793-794. doi: 10.1038/214793a0

Freissinet, C., Buch, A., Sternberg, R., Szopa, C., Geffroy-Rodier, C., Jelinek, C., et al. (2010). Search for evidence of life in space: analysis of enantiomeric organic molecules by $\mathrm{N}, \mathrm{N}$-dimethylformamide dimethylacetal derivative dependant Gas Chromatography-Mass Spectrometry. J. Chromatogr. A 1217, 731-740. doi: 10.1016/j.chroma.2009.11.009

Furukawa, Y., Chikaraishi, Y., Ohkouchi, N., Ogawa, N. O., Glavin, D. P., Dworkin, J. P., et al. (2019). Extraterrestrial ribose and other sugars in primitive meteorites. Proc. Natl. Acad. Sci. U.S.A. 116, 24440-24445. doi: 10.1073/pnas.1907169116

Glavin, D. P., Burton, A. S., Elsila, J. E., Aponte, J. C., and Dworkin, J. P. (2019). The search for chiral asymmetry as a potential biosignature in our solar system. Chem. Rev. 120, 4660-4689. doi: 10.1021/acs.chemrev.9b00474

Glavin, D. P., Dworkin, J. P., Aubrey, A., Botta, O., Doty, J. H., Martins, Z., et al. (2006). Amino acid analyses of Antarctic CM2 meteorites using liquid chromatography-time of flight-mass spectrometry. Meteoritics Planet. Sci. 41, 889-902. doi: 10.1111/j.1945-5100.2006.tb00493.x

Glavin, D. P., Dworkin, J. P., and Sandford, S. A. (2008). Detection of cometary amines in samples returned by Stardust. Meteoritics Planet. Sci. 43, 399-413. doi: 10.1111/j.1945-5100.2008.tb00629.x

Glavin, D. P., Squyres, S. W., Chu, P. C., Gerakines, P. A., Yamada, K., Parker, J. E., et al. (2018). "The CAESAR New Frontiers mission: comet surface sample acquisition and preservation," in 4th International Workshop on Instrumentation for Planetary Missions. Available online at: https://ntrs.nasa. gov/archive/nasa/casi.ntrs.nasa.gov/20180006533.pdf

Glavin, D. P., Tsou, P., Anbar, A. D., Baross, J., Beegle, L. W., Brownlee, D. E., et al. (2014). "Plume collection strategies for future icy body sample return missions," in International Workshop on Instrumentation for Planetary Missions. Available online at: https://ssed.gsfc.nasa.gov/IPM/PDF/1012.pdf

Glein, C. R., Baross, J. A., and Waite, J. H. (2015). The pH of Enceladus' ocean. Geochim. Cosmochim. Acta 162, 202-219. doi: 10.1016/j.gca.2015.04.017

Glein, C. R., Postberg, F., and Vance, S. D. (2018). “The geochemistry of Enceladus: composition and controls," in Enceladus and the Icy Moons of Saturn, eds P. M. Schenk, R. N. Clark, C. J. A. Howett, A. J. Verbiscer, and J. H. Waite (Tucson, AZ: University of Arizona Press), 39-56.

Glein, C. R., and Waite, J. H. (2020). The carbonate geochemistry of Enceladus ocean. Geophys. Res. Lett. 47:e2019GL085885. doi: 10.1029/2019GL085885

Goesmann, F., Brinckerhoff, W. B., Raulin, F., Goetz, W., Danell, R. M., Getty, S. A., et al. (2017) The Mars Organic Molecule Analyzer (MOMA) instrument: characterization of organic material in martian sediments. Astrobiology 17, 655-685. doi: 10.1089/ast.2016.1551

Gu, C., Somogyi, Á., Wysocki, V. H., and Medzihradszky, K. F. (1999). Fragmentation of protonated oligopeptides XLDVLQ (X= L, H, K or R) by surface induced dissociation: additional evidence for the 'mobile proton' model. Anal. Chimica Acta 397, 247-256. doi: 10.1016/S0003-2670(99)00409-2

Guenther, S., Koestler, M., Schulz, O., and Spengler, B. (2010). Laser spot size and laser power dependence of ion formation in high resolution MALDI imaging. Int. J. Mass Spectrometry 294, 7-15. doi: 10.1016/j.ijms.2010.03.014

Guzman, M., Lorenz, R., Hurley, D., Farrell, W., Spencer, J., Hansen, C., et al. (2019). Collecting amino acids in the Enceladus plume. Int. J. Astrobiol. 18, 47-59. doi: 10.1017/S1473550417000544

Hand, K. P., Murray, A. E., Darvin, J. B., Brinckerhoff, W. B., Christner, B. C., Edgett, K. S., et al. (2017). Report of the Europa Lander Science Definition team. National Aeronautics and Space Administration. Available online at: https://europa.nasa.gov/system/downloadable_items/50_Europa_ Lander_SDT_Report_2016.pdf

Hansen, C. J., Esposito, L., Stewart, A. I., Colwell, J., Hendrix, A., Pryor, W., et al. (2006). Enceladus' water vapor plume. Science 311, 1422-1425. doi: 10.1126/science. 1121254 
Hecht, M. H., Marshall, J., Pike, W. T., Staufer, U., Blaney, D., Braendlin, D., et al. (2008). Microscopy capabilities of the Microscopy, Electrochemistry, and Conductivity Analyzer. J. Geophys. Res. Planets 113:E00A22. doi: 10.1029/2008JE003077

Hedman, M. M., Dhingra, D., Nicholson, P. D., Hansen, C. J., Portyankina, G., Ye, S., et al. (2018). Spatial variations in the dust-to-gas ratio of Enceladus' plume. Icarus 305, 123-138. doi: 10.1016/j.icarus.2018.01.006

Hedman, M. M., Gosmeyer, C. M., Nicholson, P. D., Sotin, C., Brown, R. H., Clark, R. N., et al. (2013). An observed correlation between plume activity and tidal stresses on Enceladus. Nature 500, 182-184. doi: 10.1038/nature12371

Heller, M., Voskuilen, T., Hewson, J. C., Lane, T., Ison, A. M., Napier, M., et al. (2017). Europa Lander Alternative Sterilization Techniques Trade Study. Sandia National Laboratories. Technical Report No. SAND2017-0581PE, Albuquerque, NM, United States.

Hemingway, D. J., and Mittal, T. (2019). Enceladus's ice shell structure as a window on internal heat production. Icarus 332, 111-131. doi: 10.1016/j.icarus.2019.03.011

Hemingway, D. J., Rudolph, M. L., and Manga, M. (2019). Cascading parallel fractures on Enceladus. Nat. Astronomy. 4, 234-239. doi: 10.1038/s41550-019-0958-x

Hendrix, A. R., Hurford, T. A., Barge, L. M., Bland, M. T., Bowman, J. S., Brinckerhoff, W. B., et al. (2019). The NASA Roadmap to Ocean Worlds. Astrobiology 19, 1-27. doi: 10.1089/ast.2018.1955

Hoehler, T. M., and Jørgensen, B. B. (2013). Microbial life under extreme energy limitation. Nat. Rev. Microbiol. 11, 83-94. doi: 10.1038/nrmicro2939

Howell, S. M., and Pappalardo, R. T. (2019). Can Earth-like plate tectonics occur in ocean world ice shells? Icarus 322, 69-79. doi: 10.1016/j.icarus.2019.01.011

Hsu, H. W., Postberg, F., Sekine, Y., Shibuya, T., Kempf, S., Horányi, M., et al. (2015). Ongoing hydrothermal activities within Enceladus. Nature 519, 207-210. doi: 10.1038/nature14262

Iess, L., Stevenson, D. J., Parisi, M., Hemingway, D., Jacobson, R. A., Lunine, J. I., et al. (2014). The gravity field and interior structure of Enceladus. Science 344, 78-80. doi: 10.1126/science.1250551

Imachi, H., Nobu, M. K., Nakahara, N., Morono, Y., Ogawara, M., Takaki, Y., et al. (2020). Isolation of an archaeon at the prokaryote-eukaryote interface. Nature 577, 519-525. doi: 10.1038/s41586-019-1916-6

Inagaki, F., Hinrichs, K. U., Kubo, Y., Bowles, M. W., Heuer, V. B., Hong, W. L., et al. (2015). Exploring deep microbial life in coal-bearing sediment down to $\sim 2.5 \mathrm{~km}$ below the ocean floor. Science $349,420-424$. doi: $10.1126 /$ science.aaa6882

Jin, Z., and Bose, M. (2019). New clues to ancient water on Itokawa. Sci. Adv. 5:eaav8106. doi: $10.1126 /$ sciadv.aav8106

Johnson, C. M., Beard, B. L., and Roden, E. E. (2008). The iron isotope fingerprints of redox and biogeochemical cycling in modern and ancient Earth. Annu. Rev. Earth Planet. Sci. 36, 457-493. doi: 10.1146/annurev.earth.36.031207.124139

Kelley, D. S., Karson, J. A., Früh-Green, G. L., Yoerger, D. R., Shank, T. M., Butterfield, D. A., et al. (2005). A serpentinite-hosted ecosystem: the Lost City hydrothermal field. Science 307, 1428-1434. doi: 10.1126/science.1 102556

Khawaja, N., Postberg, F., Hillier, J., Klenner, F., Kempf, S., Nölle, L., et al. (2019). Low-mass nitrogen-, oxygen-bearing, and aromatic compounds in Enceladean ice grains. Mon. Notices R Astron. Soc. 489, 5231-5243. doi: 10.1093/mnras/stz2280

Kirk, R., Soderblom, L., Brown, R., Kieffer, S., and Kargel, J. (1995). “Triton's plumes: discovery, characteristics, and models," in Neptune and Triton, eds D. P. Cruikshank, M. S. Matthews, and A. M. Schumann (Tucson, AZ: University of Arizona Press), 949-989.

Klein, H. P. (1978). The Viking biological experiments on Mars. Icarus 34, 666-674. doi: 10.1016/0019-1035(78)90053-2

Kminek, G., Conley, C., Hipkin, V., and Yano, H. (2017). COSPAR's Planetary Protection Policy. Available online at: https://cosparhq.cnes.fr/assets/uploads/ 2019/12/PPPolicyDecember-2017.pdf (accessed February 17, 2020).

Koga, T., and Naraoka, H. (2017). A new family of extraterrestrial amino acids in the Murchison meteorite. Sci. Rep. 7:636. doi: 10.1038/s41598-017-00693-9

Konstantinidis, K., Martinez, C. L. F., Dachwald, B., Ohndorf, A., Dykta, P., Bowitz, P., et al. (2015). A lander mission to probe subglacial water on Saturn's moon Enceladus for life. Acta Astronaut. 106, 63-89. doi: 10.1016/j.actaastro.2014.09.012
Krupp, N., Roussos, E., Paranicas, C., Mitchell, D. G., Kollmann, P., Ye, S., et al. (2018). Energetic electron measurements near Enceladus by Cassini during 2005-2015. Icarus 306, 256-274. doi: 10.1016/j.icarus.2017.10.022

Kuiper, G. P. (1974) On the origin of the solar system, I. Celestial Mech. 9, 321-348. doi: $10.1007 / \mathrm{BF} 01228575$

Küppers, M., O’Rourke, L., Bockelée-Morvan, D., Zakharov, V., Lee, S., et al. (2014) Localized sources of water vapour on the dwarf planet (1) Ceres. Nature 505, 525-527. doi: 10.1038/nature12918

Lainey, V., Casajus, L. G., Fuller, J., Zannoni, M., Tortora, P., Cooper, N., et al. (2020). Resonance locking in giant planets indicated by the rapid orbital expansion of Titan. Nat. Astron. doi: 10.1038/s41550-020$1120-5$

Lakew, B., Amato, D., Fraeman, A., Falker, J., Turtle, E., Green, J., et al. (2017). Technology for NASA's Planetary Science Vision 2050. Notes from the Feb 2017 Workshop. Available online at: https://ntrs.nasa.gov/archive/nasa/casi. ntrs.nasa.gov/20170008907.pdf

Larson, S. M., Fountain, J. W., Smith, B. A., and Reitsema, H. J. (1981) Observations of the Saturn E ring and a new satellite. Icarus 47, 288-290. doi: 10.1016/0019-1035(81)90173-1

Lauretta, D. S., Balram-Knutson, S. S., Beshore, E., Boynton, W. V., Drouet d'Aubigny, C., DellaGiustina, D. N., et al. (2017). OSIRIS-REx: sample return from asteroid (101955) Bennu. Space Sci. Rev. 212, 925-984. doi: $10.1007 /$ s11214-017-0405-1

Lee, C., and Bada, J. L. (1975). Amino acids in equatorial Pacific Ocean water. Earth Planet. Sci. Lett. 26, 61-68. doi: 10.1016/0012-821X(75)90177-6

Lingam, M., and Loeb, A. (2018). Is extraterrestrial life suppressed on subsurface ocean worlds due to the paucity of bioessential elements? Astron. J. 156:151. doi: 10.3847/1538-3881/aada02

Lorenz, R. D. (2019). A Bayesian approach to biosignature detection on ocean worlds. Nat. Astronomy 3, 466-467. doi: 10.1038/s41550-019-0810-3

Lunine, J. I., Waite, J. H., Postberg, F., Spilker, L., and Clark, K. (2015). "Enceladus Life Finder: the search for life in a habitable moon," in Lunar and Planetary Science (The Woodlands, TX), abstract \#1525.

Lunine, J. I., Nakamura-Messenger, K., Mitchell, D. F., Moran, V. E., Houghton, M. B., Glavin, D. P., et al. (2018). "The CAESAR new frontiers mission: returning a sample of a cometary nucleus," in 12th European Planetary Science Congress (Berlin).

Macdonald, A. H., and Fyfe, W. S. (1985). Rate of serpentinization in seafloor environments. Tectonophysics 116, 123-135. doi: 10.1016/0040-1951(85)90225-2

MacKenzie, S. M., Caswell, T. E., Phillips-Lander, C. M., Stavros, E. N., Hofgartner, J. D., Sun, V. Z., et al. (2016). THEO concept mission: Testing the Habitability of Enceladus's Ocean. Adv. Space Res. 58, 1117-1137. doi: 10.1016/j.asr.2016.05.037

MacKenzie, S. M., Kirby, K. W., Greenauer, P. J., McCauley Rench, B., Craft, K., Neveu, M., et al. (2020). Enceladus Orbilander, a Flagship mission concept for astrobiology. Planetary Mission Concept Study for the 2023-2032 Planetary Science \& Astrobiology Decadal Survey of the United States National Academies of Sciences, Engineering, and Medicine.

Marshall, S. M., Murray, A. R. G., and Cronin, L. (2017). A probabilistic framework for identifying biosignatures using pathway complexity. Phil. Trans. R. Soc. A 375:20160342. doi: 10.1098/rsta.2016.0342

Martins, Z., Alexander, C. M. O.'D., Orzechowska, G. E., Fogel, M. L., and Ehrenfreund, P. (2007). Indigenous amino acids in primitive CR meteorites. Meteoritics Planet. Sci. 42, 2125-2136. doi: 10.1111/j.1945-5100.2007.tb01013.x

Massarweh, L., and Cappuccio, P. (2020). "On the restricted 3-body problem for the Saturn-Enceladus system: mission geometry and orbit design for plume sampling missions," in AIAA Scitech 2020 Forum (Orlando, FL).

McCollom, T. M. (2016). Abiotic methane formation during experimental serpentinization of olivine. Proc. Natl. Acad. Sci. U.S.A. 113, 13965-13970. doi: 10.1073/pnas.1611843113

McKay, C. P., Anbar, A. D., Porco, C., and Tsou, P. (2014). Follow the plume: the habitability of Enceladus. Astrobiology 14, 352-355. doi: 10.1089/ast.2014.1158

McKay, D. S., Gibson, E. K., Thomas-Keprta, K. L., Vali, H., Romanek, C. S., Clemett, S. J., et al. (1996). Search for past life on Mars: possible relic biogenic activity in Martian meteorite ALH84001. Science 273, 924-930. doi: $10.1126 /$ science. 273.5277 .924 
Melosh, H. (2019). Probabilities that Enceladus Received Life from Earth, Mars or Another Stellar System. American Geophysical Union Fall Meeting, abstract \#P24A-01. San Francisco, CA.

Mercer, C. M., Hodges, K. V., Jolliff, B. L., van Soest, M. C., Wartho, J.-A., and Weirich, J. R. (2019). Exploring the variability of argon loss in Apollo 17 impact melt rock 77135 using high-spatial resolution ${ }^{40} \mathrm{Ar} /{ }^{39} \mathrm{Ar}$ geochronology. Meteoritics Planet. Sci. 54, 721-739. doi: 10.1111/maps.13240

Mileikowsky, C., Cucinotta, F. A., Wilson, J. W., Gladman, B., Horneck, G., Lindegren, L., et al. (2000). Natural transfer of viable microbes in space: 1. From Mars to Earth and Earth to Mars. Icarus 145, 391-427. doi: 10.1006/icar.1999.6317

Nakamura, T., Tsuchiyama, A., Akaki, T., Uesugi, K., Nakano, T., Takeuchi, A., et al. (2008). Bulk mineralogy and three-dimensional structures of individual Stardust particles deduced from synchrotron X-ray diffraction and microtomography analysis. Meteoritics Planet. Sci. 43, 247-259. doi: $10.1111 / j .1945-5100.2008$.tb00620.x

NASA (2011). Procedural Requirement, 8020.12D. Available online at: https:// nodis3.gsfc.nasa.gov/displayDir. $. \mathrm{fm} ? \mathrm{t}=\mathrm{NPRand}=8020 \mathrm{ands}=12 \mathrm{D} \quad$ (accessed February 28, 2020).

National Research Council (2012). Assessment of Planetary Protection Requirements for Spacecraft Missions to Icy Solar System Bodies. Washington, DC: The National Academies Press.

Neveu, M., Desch, S. J., and Castillo-Rogez, J. C. (2017). Aqueous geochemistry in icy world interiors: equilibrium fluid, rock, and gas compositions, and fate of antifreezes and radionuclides. Geochim. Cosmochim. Acta 212, 324-371. doi: 10.1016/j.gca.2017.06.023

Neveu, M., Hays, L. E., Voytek, M. A., New, M. H., and Schulte, M. D. (2018). The ladder of life detection. Astrobiology 18, 1375-1402. doi: 10.1089/ast.2017.1773

Neveu, M., House, C. H., and Wieman, S. T. (2020). Phoebe's carbon isotope composition as evidence for self-shielding in the solar nebula. Icarus. 345:113714. doi: 10.1016/j.icarus.2020.113714.

Neveu, M., and Rhoden, A. R. (2019). Evolution of Saturn's mid-sized moons. Nat. Astronomy 3, 543-552. doi: 10.1038/s41550-019-0726-y

Nicholson, W. L. (2009). Ancient micronauts: interplanetary transport of microbes by cosmic impacts. Trends Microbiol. 17, 243-250. doi: 10.1016/j.tim.2009.03.004

Nimmo, F., Barr, A. C., Behounková, M., and McKinnon, W. B. (2018). “The thermal and orbital evolution of Enceladus: observational constraints and models," in Enceladus and the Icy Moons of Saturn, eds P. M. Schenk, R. N. Clark, C. J. A. Howett, A. J. Verbiscer, and J. H. Waite (Tucson: University of Arizona Press), 79-94.

Nurul-Abedin, M., Bradley, A. T., Misra, A. K., Bai, Y., Hines, G. D., and Sharma, S. K. (2018). Standoff ultracompact micro-Raman sensor for planetary surface explorations. Appl. Optics 57, 62-68. doi: 10.1364/AO.57.000062

Okazaki, R., Sawada, H., Yamanouchi, S., Tachibana, S., Miura, Y. N., Sakamoto, K., et al. (2017). Hayabusa2 sample catcher and container: metal-seal system for vacuum encapsulation of returned samples with volatiles and organic compounds recovered from C-type asteroid Ryugu. Space Sci. Rev. 208, 107-124. doi: 10.1007/s11214-016-0289-5

Orgel, L. E. (1998). The origin of life - how long did it take? Origins Life Evol. Biosphere 28, 91-96. doi: 10.1023/A:1006561308498

Parro, V., de Diego-Castilla, G., Rodríguez-Manfredi, J. A., Rivas, L. A., BlancoLópez, Y., Sebastián, E., et al. (2011). SOLID3: a multiplex antibody microarraybased optical sensor instrument for in situ life detection in planetary exploration. Astrobiology 11, 15-28. doi: 10.1089/ast.2010.0501

Pasek, M. A. (2008). Rethinking early Earth phosphorus geochemistry. Proc. Natl. Acad. U.S.A. 105, 853-858. doi: 10.1073/pnas.0708205105

Pizzarello, S., Huang, Y., Becker, L., Poreda, R. J., Nieman, R. A., Cooper, G., et al. (2001). The organic content of the Tagish Lake meteorite. Science. 293, 2236-2239. doi: 10.1126/science.1062614

Plesivkova, D., Richards, R., and Harbison, S. (2019). A review of the potential of the MinION ${ }^{\mathrm{TM}}$ single-molecule sequencing system for forensic applications. Wiley Interdisciplinary Rev. Forensic Sci. 1:e1323. doi: $10.1002 / \mathrm{wfs} 2.1323$

Porco, C., DiNino, D., and Nimmo, F. (2014). How the geysers, tidal stresses, and thermal emission across the south polar terrain of Enceladus are related. Astron. J. 148:45. doi: 10.1088/0004-6256/148/3/45
Porco, C. C., Dones, L., and Mitchell, C. (2017). Could it be snowing microbes on Enceladus? Assessing conditions in its plume and implications for future missions. Astrobiology 17, 876-901. doi: 10.1089/ast.2017.1665

Porco, C. C., Helfenstein, P., Thomas, P. C., Ingersoll, A. P., Wisdom, J., West, R., et al. (2006). Cassini observes the active south pole of Enceladus. Science 311, 1393-1401. doi: 10.1126/science.1123013

Postberg, F., Clark, R. N., Hansen, C. J., Coates, A. J., Dalle Ore, C. M., Scipioni, F., et al. (2018b). "Plume and surface composition of Enceladus," in Enceladus and the Icy Moons of Saturn, eds P. M. Schenk, R. N. Clark, C. J. A. Howett, A. J. Verbiscer, and J. H. Waite (Tucson, AZ: University of Arizona Press), 129-162.

Postberg, F., Kempf, S., Hillier, J. K., Srama, R., Green, S. F., McBride, N., et al. (2008). The E-ring in the vicinity of Enceladus: II. Probing the moon's interior-The composition of E-ring particles. Icarus 193, 438-454. doi: 10.1016/j.icarus.2007.09.001

Postberg, F., Kempf, S., Schmidt, J., Brilliantov, N., Beinsen, A., Abel, B., et al. (2009). Sodium salts in E-ring ice grains from an ocean below the surface of Enceladus. Nature 459, 1098-1101. doi: 10.1038/nature08046

Postberg, F., Khawaja, N., Abel, B., Choblet, G., Glein, C. R., Gudipati, M. S., et al. (2018a). Macromolecular organic compounds from the depths of Enceladus. Nature 558, 564-568. doi: 10.1038/s41586-018-0246-4

Postberg, F., Schmidt, J., Hillier, J., Kempf, S., and Srama, R. (2011). A salt-water reservoir as the source of a compositionally stratified plume on Enceladus. Nature 474, 620-622. doi: 10.1038/nature10175

Price, P. B., and Sowers, T. (2004). Temperature dependence of metabolic rates for microbial growth, maintenance, and survival. Proc. Natl. Acad. Sci. U.S.A. 101, 4631-4636. doi: 10.1073/pnas.0400522101

Priscu, J. C., Adams, E. E., Lyons, W. B., Voytek, M. A., Mogk, D. W., Brown, R. L., et al. (1999). Geomicrobiology of subglacial ice above Lake Vostok, Antarctica. Science 286, 2141-2144. doi: 10.1126/science.286.5447.2141

Rezzonico, F. (2014). Nanopore-based instruments as biosensors for future planetary missions. Astrobiology 14, 344-351. doi: 10.1089/ast.2013.1120

Riedler, W., Torkar, K., Jeszenszky, H., Romstedt, J., Alleyne, H. S. C., Arends, H., et al. (2007). MIDAS-The Micro-Imaging Dust Analysis System for the Rosetta Mission. Space Sci. Rev. 128, 869-904. doi: 10.1007/s11214-006-9040-y

Roth, L., Saur, J., Retherford, K. D., Strobel, D. F., Feldman, P. D., McGrath, M. A., et al. (2014). Transient water vapor at Europa's south pole. Science 343, 171-174. doi: $10.1126 /$ science. 1247051

Ruesch, O., Platz, T., Schenk, P., McFadden, L. A., Castillo-Rogez, J. C., Quick, L. C., et al. (2016). Cryovolcanism on Ceres. Science 353:aaf4286. doi: $10.1126 /$ science.aaf 4286

Russell, M. J., Hall, A. J., and Martin, W. (2010). Serpentinization as a source of energy at the origin of life. Geobiology 8, 355-371. doi: $10.1111 / j .1472-4669.2010 .00249 . x$

Sandford, S. A., Aléon, J., Alexander, C. M. O.’D., Araki, T., Baji, S., Baratta, G. A., et al. (2006). Organics captured from comet $81 \mathrm{P} /$ Wild 2 by the Stardust spacecraft. Science 314, 1720-1724. doi: 10.1126/science.1145013

Schopf, J. W. (1993). Microfossils of the Early Archean Apex chert: new evidence of the antiquity of life. Science 260, 640-646. doi: 10.1126/science.260.5108.640

Schulte, M., Blake, D., Hoehler, T., and McCollom, T. (2006). Serpentinization and its implications for life on the early Earth and Mars. Astrobiology 6, 364-376. doi: 10.1089/ast.2006.6.364

Sekine, Y., Shibuya, T., Postberg, F., Hsu, H. W., Suzuki, K., Masaki, Y., et al. (2015). High-temperature water-rock interactions and hydrothermal environments in the chondrite-like core of Enceladus. Nat. Commun. 6:8604. doi: $10.1038 /$ ncomms 9604

Sekine, Y., Takano, Y., Yano, H., Funase, R., Takai, K., Ishihara, M., et al. (2014). Exploration of Enceladus' water-rich plumes toward understanding of chemistry and biology of the interior ocean. Trans. Japan Soc. Aeronaut. Space Sci. Aerospace Technol. Jpn. 12, 7-11. doi: 10.2322/tastj.12.Tk_7

Selliez, L., Briois, C., Carrasco, N., Thirkell, L., Thissen, R., Ito, M., et al. (2019). Identification of organic molecules with a laboratory prototype based on the Laser Ablation-CosmOrbitrap. Planet. Space Sci. 170, 42-51. doi: $10.1016 /$ j.pss.2019.03.003

Sephton, M. A. (2002). Organic compounds in carbonaceous meteorites. Nat. Prod. Rep. 19, 292-311. doi: 10.1039/B103775G

Shearer, C. K., and Borg, L. E. (2006). Big returns on small samples: lessons learned from the analysis of small lunar samples and implications for the 
future scientific exploration of the Moon. Chemie Erde Geochem. 66, 163-185. doi: 10.1016/j.chemer.2006.03.002

Sherwood, B. (2016) Strategic map for exploring the ocean-world Enceladus. Acta Astronaut. 126, 52-58. doi: 10.1016/j.actaastro.2016.04.013

Sherwood, B., Ponce, A., and Waltemathe, M. (2019). Forward contamination of ocean worlds: a stakeholder conversation. Space Policy 48, 1-13. doi: 10.1016/j.spacepol.2018.06.005

Silveira, J. R., Raymond, G. J., Hughson, A. G., Race, R. E., Sim, V. L., Hayes, S. F., et al. (2005). The most infectious prion protein particles. Nature 437, 257-261. doi: 10.1038/nature03989

Smith, B. A., Cook, A. F., Feibelman, W. A., and Beebe, R. F. (1975). On a suspected ring external to the visible rings of Saturn. Icarus 25, 466-469. doi: 10.1016/0019-1035(75)90012-3

Southworth, B. S., Kempf, S., and Spitale, J. (2019). Surface deposition of the Enceladus plume and the zenith angle of emissions. Icarus 319, 33-42. doi: 10.1016/j.icarus.2018.08.024

Spahn, F., Schmidt, J., Albers, N., Hörning, M., Makuch, M., Seiss, M., et al. (2006). Cassini dust measurements at Enceladus and implications for the origin of the E ring. Science 311, 1416-1418. doi: 10.1126/science.1121375

Sparks, W. B., Hand, K. P., McGrath, M. A., Bergeron, E., Cracraft, M., and Deustua, S. E. (2016). Probing for evidence of plumes on Europa with HST/STIS. Astrophys. J. 829:121. doi: 10.3847/0004-637X/829/2/121

Spencer, J. S., Niebur, C. N., Kinsey, R., Spilker, T., Waite, H., Nimmo, F., et al. (2010). Enceladus Orbiter. 2013-2022 Planetary Science Decadal Survey Mission Concept Study. Available online at: https://sites.nationalacademies.org/ cs/groups/ssbsite/documents/webpage/ssb_059320.pdf (accessed February 18, 2020).

Spitale, J. N., Hurford, T. A., Rhoden, A. R., Berkson, E. E., and Platts, S. S. (2015). Curtain eruptions from Enceladus' south-polar terrain. Nature 521, 57-60. doi: $10.1038 /$ nature 14368

Spitale, J. N., and Porco, C. C. (2007). Association of the jets of Enceladus with the warmest regions on its south-polar fractures. Nature 449, 695-697. doi: 10.1038 /nature06217

Steel, E. L., Davila, A., and McKay, C. P. (2017). Abiotic and biotic formation of amino acids in the Enceladus ocean. Astrobiology 17, 862-875. doi: 10.1089/ast.2017.1673

Stern, A., Bierhaus, E. B., Calvin, W., Hendrix, A., House, C. H., Lorenzi, H., et al. (2019). NASA Planetary Protection Independent Review Board (PPIRB). Final Report. Available online at: https://www.nasa.gov/sites/default/files/atoms/ files/planetary_protection_board_report_20191018.pdf (accessed February 18, 2020).

Stone, E. C., and Miner, E. D. (1981). Voyager 1 encounter with the Saturnian system. Science 212, 159-163. doi: 10.1126/science.212.4491.159

Summons, R. E., Albrecht, P., McDonald, G., and Moldowan, J. M. (2008). Molecular biosignatures. Space Sci. Rev. 135, 133-159. doi: 10.1007/s11214-007-9256-5

Summons, R. E., Sessions, A. L., Allwood, A. C., Barton, H. A., Beaty, D. W., Blakkolb, B., et al. (2014). Planning considerations related to the organic contamination of Martian samples and implications for the Mars 2020 rover. Astrobiology 14, 969-1027. doi: 10.1089/ast.2014.1244

Sutton, M. A., Burton, A. S., Zaikova, E., Sutton, R. E., Brinckerhoff, W. B., Bevilacqua, J. G., et al. (2019). Radiation tolerance of nanopore sequencing technology for life detection on Mars and Europa. Sci. Rep. 9:5370. doi: 10.1038/s41598-019-41488-4

Takai, K., Nakamura, K., Toki, T., Tsunogai, U., Miyazaki, M., Miyazaki, J., et al. (2008). Cell proliferation at $122^{\circ} \mathrm{C}$ and isotopically heavy $\mathrm{CH}_{4}$ production by a hyperthermophilic methanogen under high-pressure cultivation. Proc. Natl. Acad. Sci. U.S.A. 105, 10949-10954. doi: 10.1073/pnas.0712334105

Takano, Y., Yano, H., Sekine, Y., Funase, R., and Takai, K. (2014). Planetary protection on international waters: an onboard protocol for capsule retrieval and biosafety control in sample return mission. Adv. Space Res. 53, 1135-1142. doi: 10.1016/j.asr.2013.12.041

Taubner, R. S., Pappenreiter, P., Zwicker, J., Smrzka, D., Pruckner, C., Kolar, P., et al. (2018). Biological methane production under putative Enceladus-like conditions. Nat. Commun. 9:748. doi: 10.1038/s41467-018-02876-y

Thomas, P. C., Tajeddine, R., Tiscareno, M. S., Burns, J. A., Joseph, J., Loredo, T. J., et al. (2016). Enceladus's measured physical libration requires a global subsurface ocean. Icarus 264, 37-47. doi: 10.1016/j.icarus.2015.08.037
Thurman, E. M. (Ed.) (1985). "Amount of Organic Carbon in Natural Waters," in Organic Geochemistry of Natural Waters, (Dordrecht: Springer), 7-65.

Treiman, A. H. (2017). "Sampling the solar system: the next level of understanding," in Planetary Science Vision 2050 Workshop (Washington, DC), abstract 1989.

Truong, N., Monroe, A. A., Glein, C. R., Anbar, A. D., and Lunine, J. I. (2019). Decomposition of amino acids in water with application to in-situ measurements of Enceladus, Europa and other hydrothermally active icy ocean worlds. Icarus 329, 140-147. doi: 10.1016/j.icarus.2019.04.009

Tsou, P., Brownlee, D. E., McKay, C. P., Anbar, A. D., Yano, H., Altwegg, K., et al. (2012) LIFE: Life investigation for Enceladus - a sample return mission concept in search for evidence of life. Astrobiology 12, 730-742. doi: 10.1089/ast.2011.0813

Tsou, P., Brownlee, D. E., Sandford, S. A., Hörz, F., and Zolensky, M. E. (2003). Wild 2 and interstellar sample collection and Earth return. J. Geophys. Res. Planets 108:E108113. doi: 10.1029/2003JE0 02109

Tyler, R. H. (2020). Heating of Enceladus due to the dissipation of ocean tides. Icarus. 348:113821. doi: 10.1016/j.icarus.2020.113821

Uesugi, M., Ito, M., Yabuta, H., Naraoka, H., Kitajima, F., Takano, Y., et al. (2019). Further characterization of carbonaceous materials in Hayabusa-returned samples to understand their origin. Meteoritics Planet. Sci. 54, 638-666. doi: $10.1111 /$ maps. 13236

Venkatapathy, E., Gage, P., Munk, M., Ellerby, D., and Stackpoole, M. (2017). "Sample return from water worlds: requirements, risks and enabling technologies," in Planetary Science Vision 2050 Workshop (Washington, DC), abstract \#1989.

Voskuilen, T., and Sakievich, P. (2017). Europa Lander Concepts Workshop: TSS Feasibility Studies (No. SAND2017-10358PE). Albuquerque, NM: Sandia National Laboratories.

Waite, J. H., Combi, M. R., Ip, W. H., Cravens, T. E., McNutt, R. L., Kasprzak, W., et al. (2006). Cassini ion and neutral mass spectrometer: Enceladus plume composition and structure. Science 311, 1419-1422. doi: 10.1126/science. 1121290

Waite, J. H., Glein, C. R., Perryman, R. S., Teolis, B. D., Magee, B. A., Miller, G., et al. (2017). Cassini finds molecular hydrogen in the Enceladus plume: evidence for hydrothermal processes. Science 356, 155-159. doi: $10.1126 /$ science.aai8703

Waite, J. H., Lewis, W. S., Magee, B. A., Lunine, J. I., McKinnon, W. B., Glein, C. R., et al. (2009). Liquid water on Enceladus from observations of ammonia and ${ }^{40} \mathrm{Ar}$ in the plume. Nature 460, 487-490. doi: 10.1038/nature 08153

Wasson, J. T., and Kallemeyn, G. W. (1988). Compositions of chondrites. Phil. Trans. $R$ Soc. London A Math. Phys. Eng. Sci. 325, 535-544. doi: 10.1098/rsta.1988.0066

Whitman, W. B., Coleman, D. C., and Wiebe, W. J. (1998). Prokaryotes: the unseen majority. Proc. Natl. Acad. Sci. U.S.A. 95, 6578-6583. doi: 10.1073/pnas.95.12.6578

Worth, R. J., Sigurdsson, S., and House, C. H. (2013). Seeding life on the moons of the outer planets via lithopanspermia. Astrobiology 13, 1155-1165. doi: 10.1089 /ast.2013.1028

Yano, H. (2017). Planetary protection Category V Unrestricted Earth Return: Hayabusa-1 and 2. Presentation to the Planetary Protection of Outer Solar System Project Team. Available online at: http://pposs.org/wp-content/ uploads/2017/03/14.-PPOSS-Case-Study-category-V-H.-Yano.pdf (accessed April 7, 2020).

Yano, H., Takano, Y., Sekine, Y., Takai, K., Funase, R., Fujishima, K., et al. (2016b). "Initial sample analyses in a capsule: a strategy of life detection and planetary protection for ocean world sample return missions," in 41st COSPAR Scientific Assembly (Istanbul, meeting cancelled), abstract \#B0.6-3-16.

Yano, H., Fujishima, K., Rothschild, L., Carbonnier, B., Guerrouache, M., Dziomba, S., et al. (2016a). "Intact capture and in-situ analysis system for biomarkers of Enceladus plume particles," in 41st COSPAR Scientific Assembly (Istanbul, meeting cancelled), abstract \#B0.6-8-16.

Younse, P., de Alwis, T., Backes, P., and Trebi-Ollennu, A. (2012). "Sample sealing approaches for Mars Sample Return caching," in IEEE Aerospace Conference (Big Sky, MT), 11. doi: 10.1109/AERO.2012.61 87048 
Zeigler, R. A., Mosie, A. B., Corrigan, C., Costello, L. J., Kent, J. J., Krysher, C. H., et al. (2019). The Apollo sample collection: 50 years of solar system insight. Elements 15, 286-287. doi: 10.2138/gselements.15. 4.286

Zhang, Y., Guo, Y., Xianyu, Y., Chen, W., Zhao, Y., and Jiang, X. (2013). Nanomaterials for ultrasensitive protein detection. Adv. Mater. 25, 3802-3819. doi: 10.1002/adma.201301334

Zolotov, M. Y. (2007). An oceanic composition on early and today's Enceladus. Geophys. Res. Lett. 34:L23203. doi: 10.1029/2007GL0 31234

Zubkov, M. V., Fuchs, B. M., Eilers, H., Burkill, P. H., and Amann, R. (1999). Determination of total protein content of bacterial cells by SYPRO staining and flow cytometry. Appl. Environ. Microbiol. 65, 3251-3257. doi: 10.1128/AEM.65.7.3251-3257.1999
Conflict of Interest: BS was employed by the company Blue Origin, LLC.

The remaining authors declare that the research was conducted in the absence of any commercial or financial relationships that could be construed as a potential conflict of interest.

Copyright (c) 2020 Neveu, Anbar, Davila, Glavin, MacKenzie, Phillips-Lander, Sherwood, Takano, Williams and Yano. This is an open-access article distributed under the terms of the Creative Commons Attribution License (CC BY). The use, distribution or reproduction in other forums is permitted, provided the original author(s) and the copyright owner(s) are credited and that the original publication in this journal is cited, in accordance with accepted academic practice. No use, distribution or reproduction is permitted which does not comply with these terms. 